\title{
Land-use changes associated with large-scale land transactions in Ethiopia
}

\author{
$\underline{\text { Tim G. Williams }}^{1}, \underline{\text { Sadie A. Trush }}^{2}, \underline{\text { Jonathan A. Sullivan }}^{3,4}, \underline{\text { Chuan Liao }}^{5}, \underline{\text { Nathan Chesterman }}^{3}, \underline{\text { Arun Agrawal }}^{3,6}, \underline{\text { Seth D. Guikema }}^{1,7}$ \\ and Daniel G. Brown ${ }^{2}$
}

\begin{abstract}
Large-scale land transactions (LSLTs) can precipitate dramatic changes in land systems. Ethiopia has experienced one of the largest amounts of LSLTs in Africa, yet their effects on local land systems are poorly understood. In this study, we quantify the direct and indirect land use and land cover (LULC) changes associated with LSLTs at eight socio-environmentally diverse sites in central and western Ethiopia. To estimate these effects, we employ a novel, two-stage counterfactual analysis. We first use a region-growing procedure to identify a "control" site with comparable landscape-level characteristics to each LSLT. Then, we sample and reweight points within each control site to further improve covariate balance. This two-stage approach both controls for potential confounding factors at multiple spatial levels and reduces the costs of extensive LULC data classification. Our results show that the majority of the reported transacted area (62\%) remained unconverted to large-scale agriculture. Most of the land that was developed into large-scale agriculture displaced smallholder agriculture (53\%), followed by conversion of woodland/shrubland $(35 \%)$ and forest $(9 \%)$. Beyond their boundaries, LSLTs indirectly influenced rates of smallholder agricultural expansion and abandonment, pointing to site dependence in how LSLTs affect adjacent land systems. In particular, the low prevalence of forest within and around these LSLTs underscores a need to move beyond measures of deforestation as proxies for LSLT effects on land systems. Our two-stage approach shows promise as an efficient method for generating robust counterfactuals and thereby LULC change estimates in systems lacking wall-to-wall LULC data.
\end{abstract}

Key Words: Ethiopia; land uselland cover change; large-scale land transactions; smallholder agriculture

\section{INTRODUCTION}

Lower- and middle-income countries have experienced a rapid increase in large-scale land investment for agricultural development. Uncertainty in food prices, demand for biofuels, and economic prospects have spurred governments and private investors to acquire large tracts of agricultural land at a pace and scale that is inarguably massive (Cotula 2009, Deininger and Byerlee 2011). Although driven by global and national forces, large-scale land transactions (LSLTs) ultimately affect socioenvironmental systems, including smallholder farming systems, at local scales. These effects are often difficult to measure because they occur both within and beyond LSLT boundaries, i.e., LSLTs generate both direct and indirect socio-environmental effects. Given the intimate connection between people, environmental function, and land systems (Messerli et al. 2015, Coomes et al. 2016), observation of changes in land use and land cover (LULC) via satellite imagery analysis offers a relevant proxy for understanding the socio-environmental effects of LSLTs. However, especially in contexts dominated by mixed croplivestock agriculture, characterizing LULC requires sensitivity to a high level of spatial detail (Sweeney et al. 2015). Consequently, both the physical extent of LSLTs in mixed crop-livestock land systems and their effects on adjacent land systems remain poorly understood.

Within LSLT borders, other studies have found several patterns relevant to LSLT-induced LULC change. Globally, LSLTs have been located in a range of LULC contexts, including cropland, shrubland, grassland, and forest (Messerli et al. 2014), suggesting direct LULC changes to intensive agriculture from smallholder agriculture, grassland, shrubland, and forest. Indeed, in forested landscapes, LSLTs can be a dominant proximate cause of deforestation (Carlson et al. 2012, Davis et al. 2015). Yet, there is a growing base of evidence that many LSLTs remain idle with no or only partial implementation (Ali et al. 2015, Teklemariam et al. 2016, Agrawal et al. 2019), as a result of speculative investments, investor inexperience, and financial constraints. Even when implementation occurs, it may take several years for direct LULC change to materialize (Magliocca et al. 2019a). In any case, because smallholder livelihoods depend on both privately held agricultural land and common-pool resource systems (Rasmussen et al. 2017), LSLTs targeting both existing smallholder farms and communal land can constitute a form of “land grabbing" (De Schutter 2011, Dell'Angelo et al. 2017).

By displacing local livelihoods, LSLTs can also significantly alter the land fabric beyond their borders. Studies examining indirect LULC changes have primarily focused on forested contexts and have most frequently found LSLTs to cause increased rates of deforestation beyond their borders (Davis et al. 2015, 2020, Ben Yishay et al. 2016, Zaehringer et al. 2018, Magliocca et al. 2019a, b). In these contexts, the amount of indirect LULC change can be influenced by factors such as the rate of direct land conversion, crop type, and other implementation characteristics (Magliocca et al. 2019a).

In mixed crop-livestock systems, which underpin African agriculture (Thornton and Herrero 2015), the indirect effects of LSLTs on LULC change are less well understood. However, there are a range of mechanisms through which LSLTs could affect adjacent smallholder land systems. Such indirect LULC change can occur in two principal directions: smallholder crop expansion and smallholder crop abandonment. Increases in the extent of smallholder agriculture, i.e., smallholder expansion, could result from population displacement, in-migration, degradation of existing farmland, rebound effects, or other shifts in economic

${ }^{1}$ Department of Industrial and Operations Engineering, University of Michigan, USA, ${ }^{2}$ School of Environmental and Forest Sciences, University of Washington, USA, ${ }^{3}$ School for Environment and Sustainability, University of Michigan, USA, ${ }^{4}$ School of Geography, Development and Environment, University of Arizona, USA, ${ }_{5}^{5}$ School of Sustainability, Arizona State University, USA, ${ }^{6}$ Gerald R. Ford School of Public Policy, University of Michigan, USA, ${ }^{7}$ Department of Civil and Environmental Engineering, University of Michigan, USA 
opportunities (Lambin et al. 2001, Lambin and Meyfroidt 2011). Smallholder expansion is more likely to occur in "frontier" regions with abundant land availability (Meyfroidt et al. 2018) and is likely to have negative implications for ecological functioning (Shennan 2008) and for livelihoods dependent on such functioning (Vosti and Reardon 1997). In contrast, reductions in smallholder agriculture and increased land abandonment, i.e., decreasing extent of smallholder agriculture, could result from displacement and out-migration, lower agricultural reliance owing to forced relocation in search of new employment opportunities, or agricultural land degradation (Lambin and Meyfroidt 2011). Reduced cultivation extents may contribute to natural ecosystem regeneration, but have negative social implications if these changes occur as a result of forced migration or soil degradation. LSLTs have the potential to accelerate or reduce both smallholder expansion and abandonment, with the net effect dependent on factors such as the amount of smallholder displacement, the level of intensification spillovers, and local land governance systems.

Ethiopia is dominated by mixed crop-livestock smallholder systems. It has experienced among the largest numbers of LSLTs in Africa (Schoneveld 2011), yet no multi-regional comparisons of LSLT-induced LULC change exist. Case studies in Ethiopia have reported LSLTs replacing smallholder agriculture with outgrower schemes (Wendimu et al. 2016) and mention conversions from forest- or rangelands that were considered "unused" by the Ethiopian government but of importance for local livelihoods (Shete and Rutten 2015, Shete et al. 2016, Nalepa et al. 2017). Further, similar to other contexts, many Ethiopian land investments have been only partially developed (Ali et al. 2015, Teklemariam et al. 2016, Shete et al. 2016). Given the distinct socio-environmental context of Ethiopia in comparison to other studied countries, the effects on LULC in Ethiopia will not necessarily mirror that of other contexts. For instance, Ethiopia has a relatively low level of forest cover, making measures of deforestation less useful or reliable indicators of impact than in other settings. A rigorous assessment of the observed effects of LSLTs on LULC in Ethiopia can therefore contribute to more generalized understanding of these phenomena, particularly as they occur in mixed crop-livestock landscapes.

In this study, we examine the direct and indirect effects of LSLTs on LULC change in Ethiopia. Our analysis spans eight contextually diverse LSLT sites in the Oromiya, BeneshangulGumz, and Gambella states of Ethiopia. We selected these sites in different administrative regions to represent a range of investor origins and encompass the diversity of landscapes targeted by LSLTs in Ethiopia. We used a semi-automated object-based image analysis (OBIA) approach with very high-resolution (VHR) imagery $(0.3-10 \mathrm{~m})$ to provide the spatial detail necessary to map LULC before and after LSLT implementation. Our meso-level analysis of micro-level data provides more accurate LULC information and context-specificity than large-scale analyses (Edelman 2013, Messerli et al. 2014, Eckert et al. 2016), and greater representativeness compared to single-site based analyses.

Generating rigorous estimates of LSLT-induced LULC change requires disentangling the effects of LSLTs from other potential causes and confounding factors. Confounding effects exist at two conceptual levels. First, there is ample theoretical and empirical evidence that LSLTs are not randomly located within a landscape
(Messerli et al. 2014, Dell'Angelo et al. 2017), i.e., there is a sitelevel selection bias. Comparing changes in and around LSLTs with other arbitrary locations is therefore inappropriate. Second, indirect LULC change often results from decision-making processes that operate at smaller scales, for instance householdlevel decisions about single or a limited number of agricultural field(s). These conditions of both site and context may therefore exert important influences on local LULC change. To address these challenges, we employ a novel, two-stage treatment-control procedure to identify counterfactuals that match both site- and point-level characteristics.

\section{DATA AND METHODS}

\section{LSLT site selection}

We selected eight sites in Ethiopia that have experienced large LSLTs (> 500 ha) within the past 20 years (Appendix 1). Each site was delineated by the georeferenced boundaries of an LSLT. We focused on three administrative regions that had experienced a high level of transaction activity: Oromiya (sites OR1, OR2, OR4, OR5), Beneshangul-Gumuz (BG3, BG4), and Gambella (GM1, GM5). The sites were purposively selected from a wider set of LSLTs (hence the non-consecutive numbering) to represent a range of socioeconomic and environmental contexts, defined by size of transaction, national origin of investor (domestic or international), initial LULC composition (cultivated or uncultivated landscape), and region within Ethiopia. To support site selection, information was compiled from academic literature, LSLT databases, and field visits. For the purposes of this study, it was necessary to select a subsample of sites from the wider pool of Ethiopian LSLTs because wall-to-wall LULC data do not exist and LULC classification is a costly process.

\section{Satellite imagery classification}

For each site, we classified LULC at two time periods, one representing conditions prior to the establishment of the LSLT (Pre-LSLT) and one after its effects are expected to have occurred (Post-LSLT). Because of the prevalence of smallholder agriculture, woodland, and shrubland, as well as our interest in mapping fine-scale changes between these states and to large-scale agriculture, our analysis required a high level of spatial detail. Such detail is generally not available in large-scale LULC datasets and can be difficult to classify with fully automated processes. Therefore, we adopted a semi-automated approach to classify VHR satellite imagery.

We obtained VHR multi-spectral imagery from sensors onboard the IKONOS (1-4 m resolution), GeoEye-1 (0.5-2 m), WorldView-1, 2 \& 3 (0.3-2 m), and Sentinel-2 (10 m) satellites. The data spanned the period of 2004 to 2016. Because of image data availability and timing of transactions, our Pre-LSLT and Post-LSLT dates differ by site and, in some cases, there was insufficient imagery available Pre-LSLT. In these cases, we selected the earliest imagery available and maintained a minimum 5-year difference between the Pre- and Post- images (Appendix 2). The implication of this limitation is that we potentially underestimate the LSLT-induced LULC change.

With this imagery, we classified LULC into nine classes (Table 1) using a semi-automated segmentation-based approach. First, we identified contiguous polygons from pixel groupings with similar spectral characteristics using the ERDAS IMAGINE Objective 
Table 1. Land use and land cover classes. Values in parentheses under the aggregated classes represent the inter-rater reliability.

\begin{tabular}{|c|c|c|}
\hline$\underline{\text { LULC class }}$ & Sub-class & Description \\
\hline $\begin{array}{l}\text { Smallholder } \\
(80.7 \%)\end{array}$ & $\begin{array}{l}\text { Smallholder } \\
\text { agriculture } \\
\text { Rural settlement }\end{array}$ & $\begin{array}{l}\text { Cultivated areas }(<10 \text { ha) with a mosaic of different subsistence crops (primarily cereals), fallow area, } \\
\text { and cycle of crop maturity; some settlements and sparse tree cover. } \\
\text { Natural and impermeable surfaces, including roads and dense housing. }\end{array}$ \\
\hline $\begin{array}{l}\text { Large-scale agriculture } \\
(55.4 \%)\end{array}$ & & $\begin{array}{l}\text { Cultivated fields ( }>10 \text { ha) with vegetation pattern indicating uniform planting (monocrop) and harvest } \\
\text { cycles; may include tree crops and is clearly visible from satellite imagery. }\end{array}$ \\
\hline $\begin{array}{l}\text { Forest } \\
(73.9 \%)\end{array}$ & & Densely forested area with $70 \%-100 \%$ closed canopy cover \\
\hline $\begin{array}{l}\text { Woodland/shrubland } \\
(78.9 \%)\end{array}$ & & $\begin{array}{l}\text { Mixed area of small trees, short bushes, shrubs and open grassland; } 10 \%-70 \% \text { ground coverage, small } \\
\text { trees }(<10 \%) \text {. }\end{array}$ \\
\hline $\begin{array}{l}\text { Bare/exposed soil } \\
(19.6 \%)\end{array}$ & & Land with very sparse grass or completely no vegetation cover. \\
\hline Other $(36.9 \%)$ & $\begin{array}{l}\text { Development } \\
\text { Water } \\
\text { Wetland }\end{array}$ & $\begin{array}{l}\text { Major roads and urban or industrial infrastructure with a minimum mapping unit of } 30 \text { meters. } \\
\text { Natural and artificial water bodies: rivers, lakes, and reservoirs. } \\
\text { Swampy and waterlogged in the wet season (June-August), dry in the dry season (December-- } \\
\text { February). }\end{array}$ \\
\hline
\end{tabular}

tool. Next, all polygon segments were manually classified by trained analysts into the nine LULC types, which were then combined into six aggregated classes to both reflect categories of interest and minimize inter-class confusion (measured using interrater reliability). Appendix 2 provides details.

\section{LULC change outcomes}

To assess direct LULC change, i.e., within the LSLT boundaries, we measured transitions between the six aggregated LULC classes in Table 1. For each site, we calculated the fraction of land in each class in the Pre- and Post-LSLT periods as well as the area transitioning between each combination of classes.

We interpreted an LSLT's indirect effects to comprise effects on agricultural activities and livelihoods adjacent to the LSLT boundaries, here determined as LULC change within a $10 \mathrm{~km}$ buffer of each LSLT (henceforth "treatment site"). The buffer distance was set to reflect distances over which indirect impacts were expected to extend, based on our discussions with in-country partners and surveys conducted in the field (Hajjar et al. 2019). We assessed two indirect LULC change outcomes: smallholder expansion, describing the conversion of any non-smallholder land to smallholder agriculture $\left(\mathrm{Y}_{1}\right)$; and smallholder abandonment, describing the conversion of land from smallholder agriculture to any non-smallholder LULC $\left(\mathrm{Y}_{2}\right)$.

Because the assessment of indirect LULC change is based on LULC data alone, we cannot directly make inferences about the mechanisms contributing to these outcomes, e.g., whether increased smallholder abandonment is due to LSLT-induced displacement. Further, because of the diversity of LULC across our sites, we did not distinguish between, for example, smallholder expansion into forest or into woodland-shrubland; given the very low level of forest cover in some sites, such distinctions were not always meaningful and could not be easily compared between sites. Finally, we excluded BG4, GM1, and GM5 from our assessment of smallholder abandonment $\left(\mathrm{Y}_{2}\right)$ because less than $5 \%$ of their area initially comprised smallholder agriculture.

\section{Two-stage treatment-control approach}

\section{Rationale and overview}

Because LULC change occurs even in the absence of LSLTs, estimating an LSLT's indirect impact requires an appropriate counterfactual, i.e., a proxy for LULC change outcomes in the absence of the LSLT. Causal analyses of indirect LULC change frequently select counterfactual observations by sampling points from a wider buffer region, e.g., up to $100 \mathrm{~km}$ or further, around the central treatment site (Davis et al. 2015). Such "donut" approaches are pragmatic when wall-to-wall LULC outcome data are available (e.g., Hansen et al. 2013). However, because of the high data fidelity required for analyses of LULC in mixed croplivestock systems and the paucity of large-scale classified datasets, a donut-based approach would require classification of a massive land area, adding considerable time and expense to the analysis. Beyond these pragmatic considerations, such approaches are conceptually questionable in the context of LSLTs, which are assigned to the landscape as spatially contiguous parcels, rather than isolated points. Point-based matching using counterfactuals from a wider donut region may therefore miss important landscape-level characteristics that influence the politics and pragmatics of land acquisition and transaction.

Our two-stage approach to overcome these challenges (Fig. 1) used a region-growing process in the first stage to identify a characteristically similar "control site" that is equivalent in size and within $30 \mathrm{~km}$ of each treatment site. In the second stage, we sampled points from within each treatment and control site and reweighted the control points so as to maximize the site-level covariate balance. Whereas the first step aimed to sub-sample from the $30 \mathrm{~km}$ donut to identify a comparable, spatially contiguous polygon and reduce the LULC classification burden, the second step aimed to use the data from each control site systematically to reduce bias in the LULC change estimates. For both stages, we utilized covariates for which wall-to-wall public datasets exist.

\section{Stage 1: Control site selection}

LSLTs are assigned to the landscape as contiguous polygons when land deals are made. This location assignment is likely influenced by landscape-level characteristics that influence the costs and politics of acquiring land and converting it to large-scale production. Previous studies have shown that LSLTs globally may preferentially target "the commons" (Dell'Angelo et al. 2017) and sparsely populated, poorer, forested areas (Liao et al. 2020). Additionally, global assessments of LSLT locations have used population density, agricultural production potential, and 
Fig. 1. (A) Site locations within Ethiopia and (B) schematic illustration of the two-stage treatment-control approach.

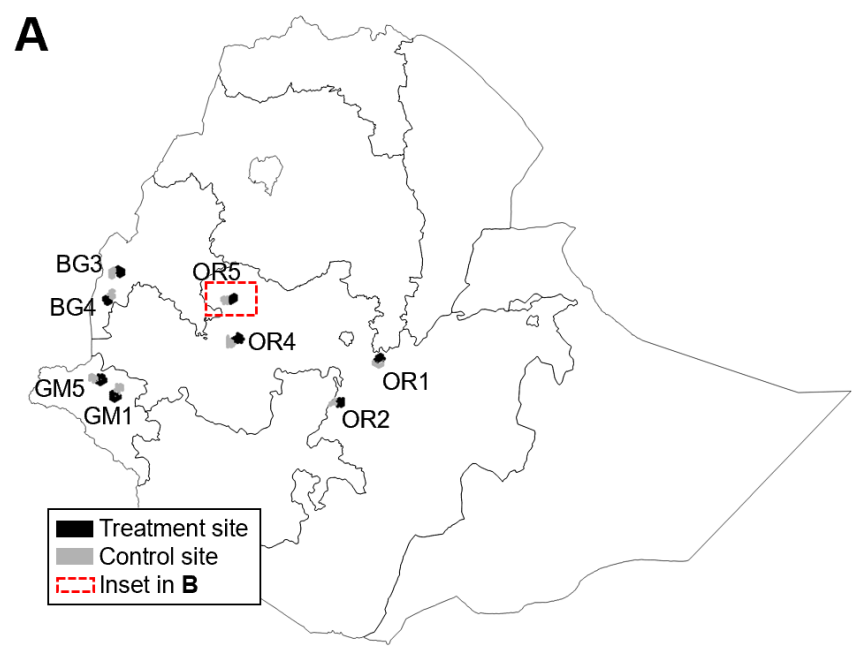

B

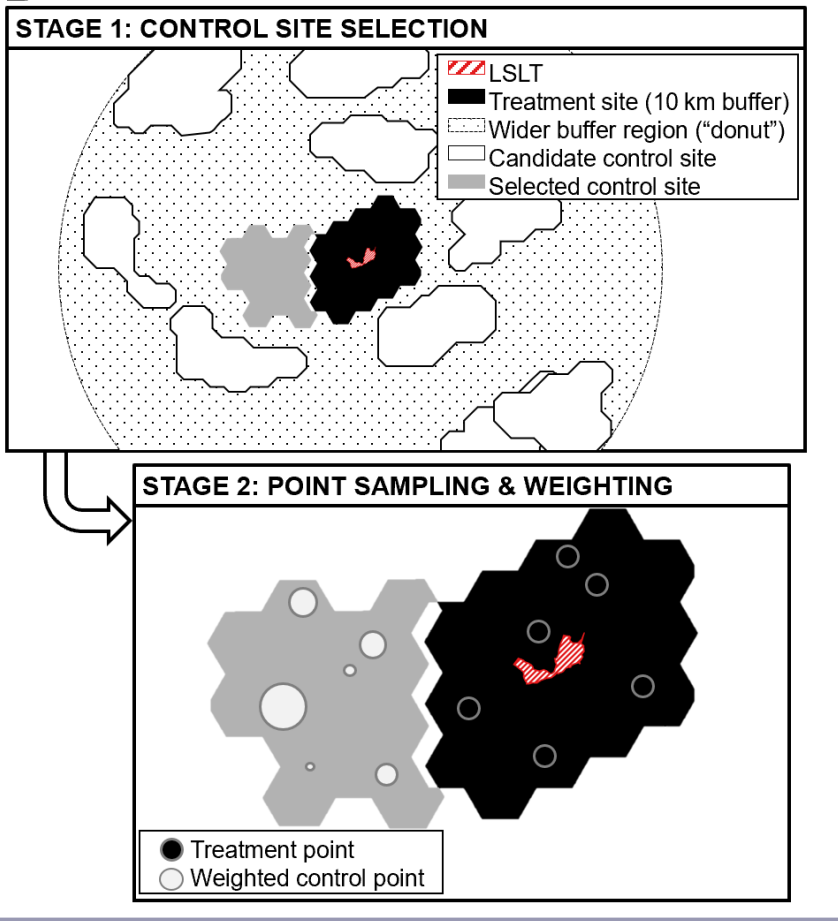

accessibility as explanatory factors (Messerli et al. 2014, Rulli and D'Odorico 2014). Accordingly, in Ethiopia, a "Land Bank" established in 2008 set aside close to 3.5 million hectares of purportedly unused land for large-scale development (Rahmato 2011, Nalepa et al. 2017).

The first stage sought to control for this site-level selection bias by identifying a similar-sized control site near each treatment site that minimizes their difference across four confounding factors: elevation, population density, night light index, and forest cover. The selected covariates encompass notions of production potential (elevation, forest cover) and accessibility (population density, night light index) found to be relevant in the previous studies mentioned above. Data sources and additional justification are in Appendix 3. We resampled these covariate raster images to a spatial resolution of $1 \mathrm{~km}$ and rescaled their values between 0 and 1 .

To select contiguous control sites, we randomly generated 30 candidate control polygons of identical size and within $30 \mathrm{~km}$ of each LSLT. Candidate control polygons were generated using the following procedure: (1) randomly select a pixel within $30 \mathrm{~km}$ of the land transaction boundary but outside the treatment site, i.e., from the donut; (2) determine the neighboring pixels of the selected pixel, and evaluate the sum of squared difference, i.e., Euclidean distance, between values at each neighboring pixel and the treatment area on the four matching covariates; (3) select the pixel that shows the smallest difference compared to the characteristics of the treatment area and merge it with the selected pixel(s) in the previous step; (4) continue steps 1-3 until the total area of the grouped pixels reaches the size of the treatment area and convert the grouped pixels into a polygon; (5) repeat steps 1 4 for 30 times; and (6) select the control site as the polygon with the lowest sum of squared differences over all matching covariates. In this process, no constraints were imposed on the shape of the control polygons, but because of spatial autocorrelation in the covariate data they tended to emerge as compact shapes, i.e., goodfitting pixels are likely to be adjacent.

Stage 2: Point sampling and weighting

Indirect LULC change within each site is influenced by processes at sub-site scales. For example, the conversion of a section of forest to an agricultural field is only likely to occur if it is financially and practically feasible. Many factors may theoretically influence these sub-site LULC change outcomes, and these factors are not necessarily perfectly balanced between the treatment and control sites. We therefore conducted a pointlevel rebalancing to prioritize data from areas within each control site that most closely match the respective treatment site.

We first generated a systematic random spatial sample of a prespecified number of points from each treatment and control site. The LULC data were stored as polygons, i.e., vector data, and we sampled points within polygons that were (1) outside of the LSLT boundary and (2) not in large-scale agriculture in the Post-LSLT period. The latter condition was set because some sites contained large-scale agriculture outside of the LSLT boundary in the Post-LSLT period. These may have been due to inaccuracies in the georeferenced LSLT boundaries, so we excluded these areas from the sampling procedure to ensure that sample points represented indirect effects.

There is a trade-off when sampling points: larger sample sizes enable higher statistical power but the points become increasingly spatially correlated, i.e., LULC changes in one location will influence the conditional probability of changes in a nearby location. Spatial autocorrelation is problematic because it introduces data redundancy and can artificially reduce the variance of statistical estimates (Griffith 1987), thereby conveying a greater level of confidence than is warranted. We used Moran's I to test for residual spatial autocorrelation in the LULC change outcomes after controlling for the effects of our covariates. We experimented with a range of sample sizes and selected the largest sample size for which the residuals were not significantly spatially correlated. 
After sampling the points, we used an entropy balancing algorithm (Hainmueller 2012) to calibrate a weight for each control point to improve the site-level covariate balance between the treatment and (reweighted) control points. The entropy balancing procedure seeks to retain as much data as possible from the control site, i.e., keep control point weights as close as possible to one, while satisfying balance criteria. Entropy balancing has been shown to achieve estimates that are comparable to matching (Busso et al. 2014), but its data-retention feature makes balancing advantageous in our context relative to other matching approaches that rely on a large pool of control observations. This is because we wanted to avoid excessively discarding control observations, as each had been sampled from an area of the same size as the treatment site, i.e., the control site.

The entropy balancing controlled for the following confounding factors: slope, soil productivity, population density, forest cover, and distance to road (Appendix 3). This selection was informed by previous point-level causal analyses of land change in low- and middle-income countries (Blackman 2013, Nolte et al. 2013, Ferraro and Hanauer 2015, Ben Yishay et al. 2016) as well as hypotheses about the additional drivers of our selected LULC change outcomes. For instance, high population densities in areas with reasonable market access (distance to road) may contribute to agricultural expansion (Lambin et al. 2001). In contrast, low soil productivity may drive smallholders to abandon agricultural production. The selected covariates contain some overlap with those used for the first-stage procedure, but we replaced nightlight index with distance to a major road and replaced elevation with slope and soil productivity as these variables are more relevant for describing agricultural LULC change at a point level. We did not control for household-level factors, e.g., demographics or wealth, because it would have required exhaustive surveying of all households in these regions, spatial delineation and assignment of individual agricultural fields to households, and association of information about multiple households to communally managed land. We instead used the selected socioenvironmental covariates as proxies for household-level drivers of LULC change.

\section{Assessing covariate balance}

We examined how each stage of the two-stage procedure affected the covariate balance, i.e., the degree of similarity between the treatment site and the counterfactual. For the first stage, we compared the balance between the wider donut region (i.e., the null counterfactual) and the selected control site (the first-stage counterfactual). For the second stage, we compared the balance before and after the rebalancing procedure. We ran this calculation twice for the second stage, once using points sampled from the control site and once using points sampled from the 30 $\mathrm{km}$ donut region. The latter case aimed to provide an estimate of the balance that could have been achieved via the standard, donutbased approach with rebalancing. In all cases, we used the absolute standardized mean difference (ASMD) to assess covariate balance between the treatment $(T)$ and control $(C)$ observations:

$$
A S M D=\frac{\left|\mu_{T}-\mu_{C}\right|}{\sqrt{\frac{\sigma_{T}^{2}+\sigma_{C}^{2}}{2}}}
$$

where the mean $(\mu)$ and variance $\left(\sigma^{2}\right)$ were calculated using the weighted control points in the second stage. In general, an AMSD less than 0.1 is considered acceptable (Austin 2009).

\section{Estimation strategy}

We quantified indirect LULC change at a site-level, calculating the difference in the probability that a point in the treatment site experiences the LULC change outcome $\left(\mathrm{Y}_{1}\right.$ or $\left.\mathrm{Y}_{2}\right)$ relative to a reweighted point from the corresponding control site. In all cases, we repeated the point-based sampling and analysis procedure 100 times with different random seeds to provide confidence intervals on our estimates. To verify the robustness of the LULC change estimates to the sampling and rebalancing procedure, we also estimated indirect LULC change under two alternative approaches: (1) using genetic matching, an optimization-based matching algorithm that provides a covariate balance at least as good as that of propensity score matching or Mahalanobis distance matching (Diamond and Sekhon 2013); and (2) sampling and rebalancing 1000 points in each treatment and control site.

\section{RESULTS}

\section{Initial LULC compositions}

In the Pre-LSLT period, the sites in Oromiya (OR1, OR2, OR4, and OR5) primarily comprised smallholder agriculture (Fig. 2). The sites in Gambella (GM1 and GM5) and Beneshangul-Gumuz (BG3 and BG4), with generally lower population densities (Appendix 4), were primarily uncultivated, i.e., forest, woodland/ shrubland, and bare soil. With the exceptions of GM5 that had a large amount of bare soil in its Treatment site and GM1 that had unbalanced amounts of smallholder agriculture, LULC is generally relatively similar between the paired treatment and control sites. Visual cross-checking of the classified LULC data with the original imagery confirmed that the bare soil in GM5 is not due to classification error.

The land transacted as part of the LSLTs exhibited differences in comparison to the surrounding treatment buffer areas. Notable examples include OR 1 and OR2, in which the LSLTs were entirely located in smallholder agricultural land and woodland/ shrubland, respectively. Additionally, in all BG and GM sites, the proportion of smallholder agricultural land was lower in the LSLT than the surrounding buffer area.

Three sites (GM1, OR4, and OR5) showed signs of large-scale agriculture in the Pre-LSLT period (Fig. 2). In all cases, this was because insufficient imagery was available before the LSLT establishment date (Appendix 2). Although the Pre-LSLT period in these cases is not a true representation of LULC prior to LSLT execution, it is the best possible and each of these sites does show clear increase in large-scale agriculture into the Post-LSLT period. The implication of large-scale agriculture presence in the PreLSLT images for these sites is that our analysis will underestimate the extent of transition to such agriculture as a result of LSLTs.

\section{Direct LULC changes}

Across all sites, $35 \%$ of the transacted area was located in woodland-shrubland, $32 \%$ in smallholder farms, $8 \%$ in forest, and $6 \%$ in bare soil (Fig. 3). Twenty percent of the area was already developed as large-scale agriculture. At the site-level, the LSLTs were located in a variety of different landscapes, including almost exclusively uncultivated LULC, i.e., forest and woodland/ shrubland (BG3, BG4, OR2, GM1, GM5), mixes of uncultivated 
Fig. 2. Site-level land use and land cover (LULC) in the Pre-LSLT (large-scale land transaction) period. The "Trt" bars represent the buffer area in each treatment site (i.e., surrounding the LSLT). The "Other" class (Table 1) is not displayed.

\section{BG3}

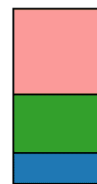

Ctrl

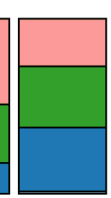

Trt

OR1

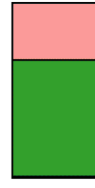

Ctrl
BG4

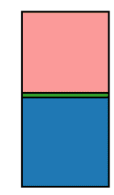

Ctrl

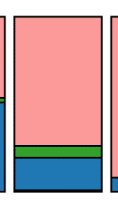

Trt
OR2

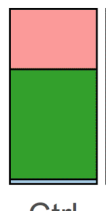

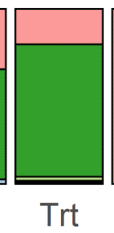

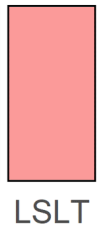

GM1

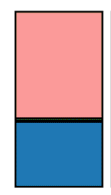

Ctrl

OR4

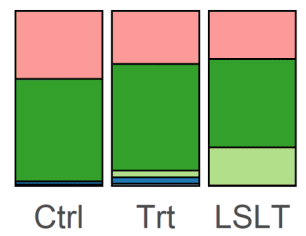

GM5

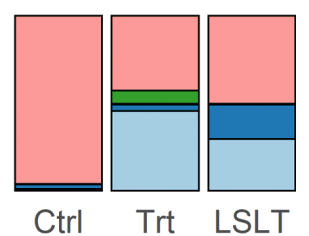

OR5

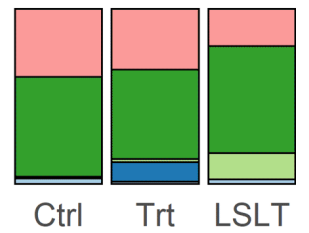

Woodland-shrubland $\square$ Smallholder

Large-scale

Forest

Bare-soil

Fig. 3. Direct land use and land cover (LULC) changes, i.e., within large-scale land transaction (LSLT) boundaries, aggregated over all eight sites. The widths of the bars indicate the fraction of each LULC type and transition. For clarity, transitions smaller than $5 \%$ of the largest transition are not displayed.

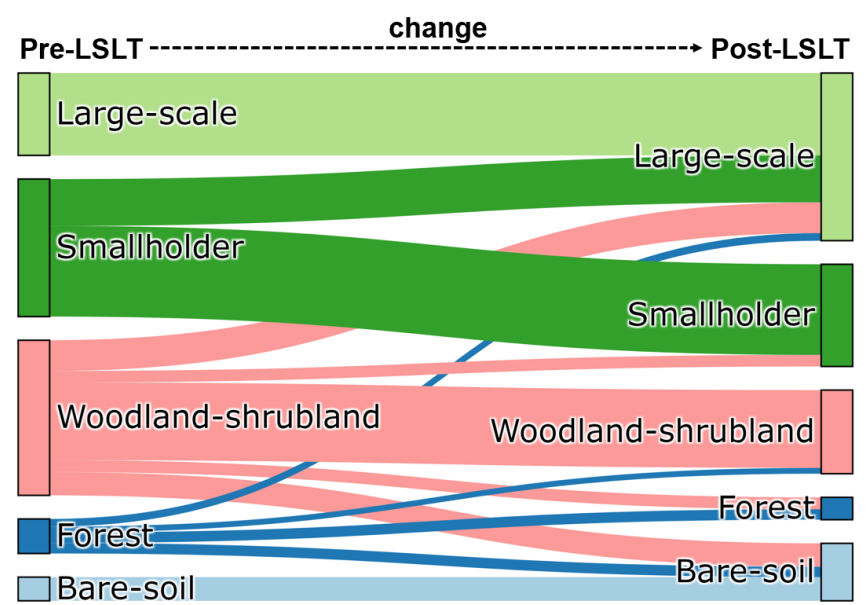

and smallholder-cultivated (OR4 and OR5), and exclusively smallholder (OR1; Fig. 4).

Only $38 \%$ of the overall transacted area was developed as largescale agriculture in the Post-LSLT period (Fig. 3). In no sites was the area within the LSLT boundary fully developed (Fig. 4), and in some cases less than $10 \%$ of the transacted area was developed (OR2 and GM5). Of the land that was developed into large-scale agriculture during the analysis period, the majority involved conversion from smallholder agriculture (53\%; primarily in OR 1 ,
OR4, and OR 5) and woodland/shrubland (35\%; OR2, OR 4, BG3, BG4), with a smaller proportion of conversion from forests $(9 \%$; primarily BG3). Various other LULC changes occurred within the LSLT boundaries, with sites experiencing deforestation (OR5, GM5), reforestation (most notably BG4), and expansion of smallholder agriculture (OR5).

\section{Indirect LULC changes}

Bias reduction in the two-stage procedure

The control sites selected by the first-stage region growing algorithm generally had comparable levels of bias to the wider donut regions, which was above the acceptable AMSD limit of 0.1 (Fig. 5A; Austin 2009). Thus, in most cases, the site selection process yielded a pool for control samples that was comparable to random sampling from the donut but only approximately $1 / 8$ th of the size, i.e., a circle with $10 \mathrm{~km}$ radius versus a donut with 30 $\mathrm{km}$ outer radius and $10 \mathrm{~km}$ inner radius. The algorithm, however, was not able to find a comparably sized area with comparable bias in the GM1 site. In particular, there were large disparities in the elevation and population density covariates for this site (Appendix 4). This could be due to large diversity in the covariates across GM1's buffer region, or that the LSLT was targeted at a non-representative area within the landscape.

The point-level indirect LULC change analysis entailed sampling 75 points from each treatment and control site to achieve an appropriate balance between statistical power and spatial independence (Appendix 4). Rebalancing within the sampled control points effectively reduced bias to within acceptable limits across all sites and outcomes (Fig. 5B and C). A donut-based approach, i.e., sampling and rebalancing points from the entire $30 \mathrm{~km}$ donut, led to acceptable bias in all instances except outcome $Y_{1}$ in OR1, in which the algorithm was unstable, with several points receiving extremely large weights. Because we included the donut-based rebalancing solely for comparative purposes, we do not dwell on this particular instability. 
Fig. 4. Direct land use and land cover changes within each site. For clarity, transitions smaller than $5 \%$ of the largest transition within each site are not displayed.

BG3

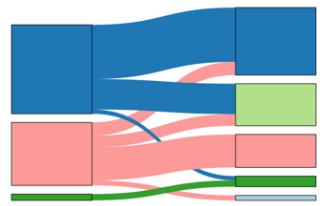

OR1

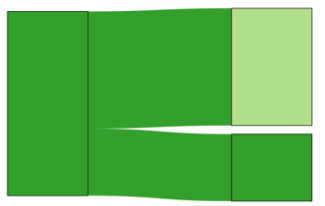

Woodland-shrubland
BG4

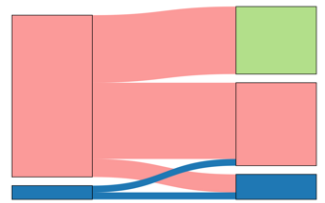

OR2

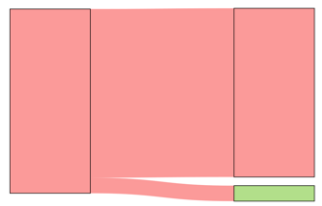

GM1

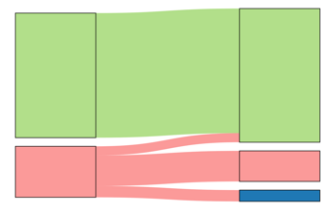

OR4

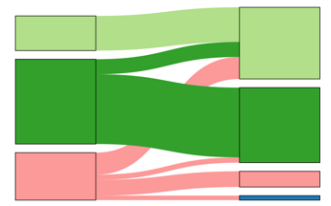

GM5

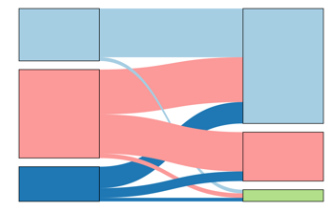

OR5

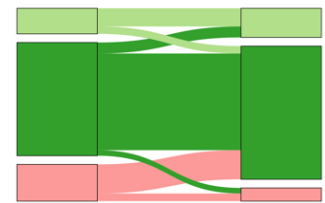

Smallholder

Bare-soil

Fig. 5. Covariate balance at the first stage site selection (A) and the second stage point rebalancing (B and $\mathrm{C}$ ). The second stage is shown twice because the analysis for each outcome (Y1 and Y2) required sampling points from different areas. BG4, GM1, and GM5 were excluded in the assessment of Y2 because they contained very little smallholder agriculture Pre-LSLT (largescale land transaction). For this figure, we averaged the absolute standardized mean difference over all covariates. The individual covariates are shown in Appendix 4.

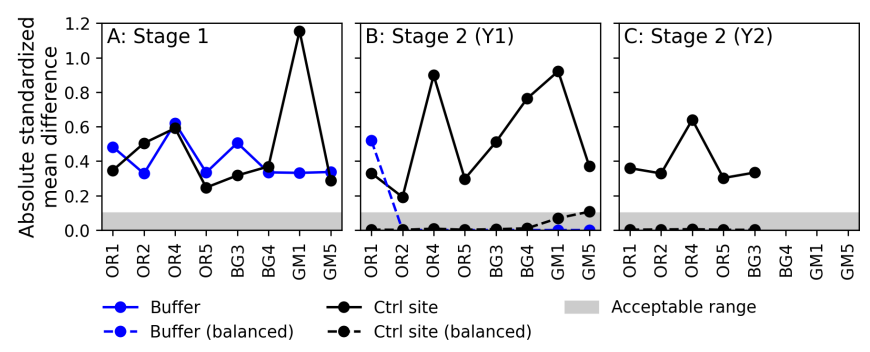

Indirect LULC change outcomes

Although all treatment sites experienced some level of both smallholder agricultural expansion and abandonment (Fig. 6; 0stage boxplots), the counterfactual-based analysis shows that LSLTs led to both increased and decreased rates of both outcomes (Fig. 6). However, for both outcomes, the indirect LULC change estimates were site-specific and generally not statistically significant. OR 1 was the only site with estimates consistent across $95 \%$ of the sampling replications. In OR 1 , where the LSLT was located almost entirely in existing smallholder agriculture (Fig. 2), the LSLT increased the probability of smallholder expansion in the treatment buffer area by approximately $20 \%$ and decreased smallholder abandonment by 5\%-10\%. The other sites displayed a range of effects. For instance, the trends in OR4 are in the
Fig. 6. Indirect land use and land cover (LULC) change estimates and the effect of the two-stage treatment-control approach. The 0 -stage distributions represent the probability of each LULC change outcome in points sampled from the treatment site buffer area only, 1-stage represents treatment/ control site differences, and 2-stage represents differences between treatment and reweighted control points. Box plot whiskers indicate $5 \%$ and $95 \%$ intervals on the estimates across the 100 sampling replications.

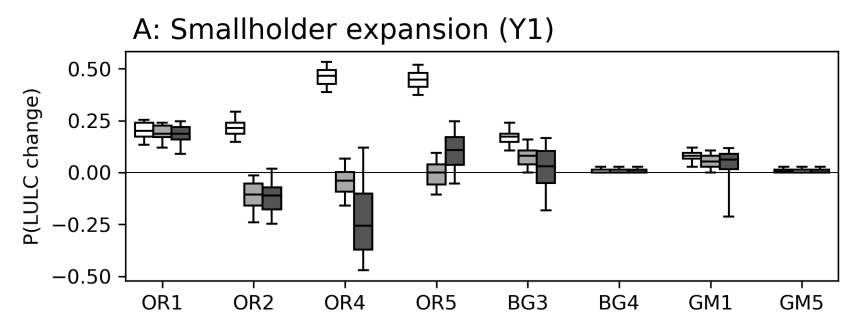

B: Smallholder abandonment (Y2)

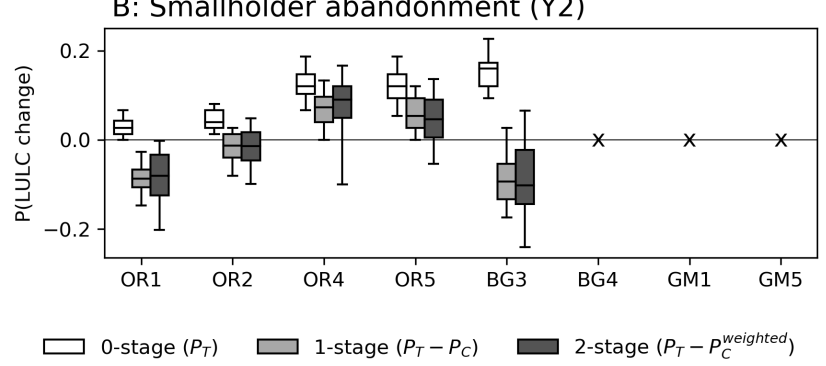

opposite direction to those in OR1 for both outcomes, i.e., the LSLT in OR4 decreased smallholder expansion and increased smallholder abandonment. These effects were large in magnitude, though not significant at a 5\% level. 
In the Oromiya sites, which contained the highest levels of existing smallholder agriculture, the LSLTs had divergent effects on smallholder expansion. This divergence was associated with the proportion of smallholder agricultural land inside the LSLT boundary (Fig. 2); the Oromiya sites in which the LSLT was located on primarily smallholder agricultural land (OR1, OR5) experienced increased smallholder expansion spillover effects. In contrast, the sites with lower amounts of smallholder agricultural land in the transacted region (OR2, OR4) experienced decreased rates of smallholder expansion. Sites outside Oromiya with low existing smallholder agriculture (BG4, GM5) showed very little expansion of smallholder agriculture over the analysis period in either the treatment or the control sites. The treatment sites with moderate existing smallholder agriculture (GM1 with 17\% and BG3 with 35\%) both experienced small levels of smallholder expansion over the analysis period, which was marginally higher than in the respective control sites (Fig. 6).

The results were robust to the choice of the second-stage bias reduction method, i.e., genetic matching produced similar indirect LULC change estimates to entropy balancing (Appendix 4). Using a much larger sample size (sampling 1000 points within each treatment and control site) led to similar median estimates but much narrower confidence bands, demonstrating the risks of autocorrelation in sample points, i.e., increased tendency to reject the null hypothesis of no effect (Appendix 4).

\section{DISCUSSION}

Our results provide evidence of LSLTs having limited levels of implementation (in the Post-LSLT period), displacing smallholder agriculture, and causing divergent spillover effects in surrounding landscapes. Our meso-level analysis and two-stage approach have improved our ability to quantify and generalize the link between observed LULC change and the presence of LSLTs over case studies and prevailing donut-based matching approaches. However, we can neither yet identify the mechanisms through which the observed effects arose nor quantify the specific environmental and social effects of the LULC changes. We therefore use these results to raise questions for further investigation using additional social and environmental data.

\section{Location and development of LSLTs}

The eight LSLTs were located in diverse socio-environmental landscapes (Fig. 2). The sites in Oromiya, closer to the capital Addis Ababa than the other sites and with substantial existing smallholder agriculture, could be described as "densely populated and easily accessible croplands," which represents around onethird of land deals globally (Messerli et al. 2014:449). The sites in Gambella and Beneshangul-Gumuz, with average population densities as low as 3 people $/ \mathrm{km}^{2}$ and considerably lower levels of existing smallholder agriculture, correspond most closely to a "moderately accessible and moderately populated shrub- or grassland" category, which represents an estimated one quarter of land deals globally (Messerli et al. 2014:449). Thus, even within a single country, the socio-environmental contexts targeted by LSLTs can differ widely.

The LULC within the LSLT boundaries prior to transaction was not always representative of the surrounding landscape. For example, in all BG and GM sites the proportion of uncultivated
LULC, i.e., woodland/shrubland and forest, was higher within the LSLT than the surrounding buffer area (Fig. 2). This is consistent with other evidence of LSLTs being targeted in the commons (Dell'Angelo et al. 2017) or areas of land that are assumed to be unproductive or unused (Deininger and Byerlee 2011, D'Odorico et al. 2017, Liao et al. 2020). Ethiopia's Land Bank potentially contributes to this result (Rahmato 2011). Although we cannot definitively equate our uncultivated land classes with the term "commons," descriptions of Ethiopian livelihoods are generally consistent with this assertion (Shete and Rutten 2015, Nalepa et al. 2017).

Across all sites, the majority $(62 \%)$ of the transacted area remained unconverted to large-scale agriculture in the Post-LSLT period. This suggests that any benefits to surrounding smallholder populations that might come from regional investments or employment may not be realized (Keeley et al. 2014, Shete and Rutten 2015, Agrawal et al. 2019, Ali et al. 2019) because of reasons such as land speculation or unanticipated logistical challenges. Of the land developed into large-scale agriculture over the analysis period, $53 \%$ originated from smallholder agriculture. This result sets Ethiopia apart from many other countries undergoing LSLTs, where other forms of land and livelihood dispossession, including deforestation, can dominate (Jiao et al. 2015). The prominence of smallholder agriculture within our sample of LSLTs highlights the potential importance of LSLTs in affecting smallholder livelihood transitions in Ethiopia, affecting such conditions as capitalization of agriculture, tenure insecurity, loss of livelihood assets, and population displacement (Keeley et al. 2014, Moreda 2015, Oberlack et al. 2016, Hajjar et al. 2019, Nanhthavong et al. 2021).

\section{Indirect LULC change}

That LSLTs can lead to highly divergent spillover effects suggests that LSLT contexts and implementation have important implications for surrounding land systems. The first outcome we assessed, agricultural expansion, replaces uncultivated land cover and therefore implies reductions in biodiversity and natural ecosystem function. We found two distinct conditions under which LSLTs led to increased smallholder expansion. The first represented sites with low proportions of existing smallholder agricultural land (BG3 and BG4). In these sites, which are likely closer to the agricultural frontier, the LSLTs may have employed migrant workers who established their own farms in the vicinity (Fox et al. 2018, Zaehringer et al. 2018), or triggered demographic shifts away from traditional hunter-gatherer livelihoods. Although we cannot derive measures of land-use intensity from our data, the relative role that intensification may have played in comparison to the measured land-use extensification is an important factor worth pursuing further (Meyfroidt et al. 2018). The second context with increased smallholder expansion was in sites that consisted primarily of smallholder agricultural land in both the buffer and the transacted area (OR1 and OR5). Here, the observed effects may be due to households claiming new land to compensate for agricultural land lost through the transaction (Zaehringer et al. 2018). Whether or not this sufficiently compensated for lost smallholder agricultural land remains a question, though evidence from other countries has shown it frequently does not (Oberlack et al. 2016, Nanhthavong et al. 2021). 
LSLTs led to decreased smallholder expansion in sites with both moderate levels of smallholder agriculture in the buffer area and lower amounts of smallholder agriculture in the transacted area (OR2 and OR4). There are several potential explanations for this outcome: (1) increased employment opportunities for local populations, reducing their reliance on smallholder agriculture; (2) spillover productivity increases, reducing the need for smallholders to expand their cultivated land; (3) out-migration from the treatment site; or (4) constraints on smallholder expansion in the treatment sites. There is little evidence supporting the first two mechanisms in Ethiopia (Shete and Rutten 2015, Teklemariam et al. 2016, Wendimu et al. 2016, Ali et al. 2019). The possible effects of LSLTs on displacement, migration, and land tenure are important mechanisms worth exploring further.

LSLTs also led to both increased and decreased rates of smallholder abandonment. The smallholder abandonment outcomes were generally smaller in magnitude, and again our estimates were mostly statistically insignificant. Nevertheless, the LSLTs may have increased out-migration of existing smallholder populations or even contributed to land degradation (Shete et al. 2016, Debonne et al. 2021). Smallholder abandonment cooccurred with both increased and decreased rates of smallholder expansion (OR4 versus OR5), and further work is needed to understand the mechanisms contributing to this divergence.

\section{Two-stage approach and meso-level LULC change analysis}

We employed a novel, two-stage treatment-control approach to estimate the indirect LULC change effects. This approach has both pragmatic and conceptual advantages. Pragmatically, our approach allowed us to collect and classify VHR imagery, which would have been impractical had we used more extensive regions from which to sample control points (requiring eight times the volume of data). This enabled us to have greater confidence in our data and to explore both land use and land cover in our assessments. Conceptually, our design explicitly controlled for site- and situation-level conditions, yielding counterfactuals that are more theoretically justified; compared to traditional pointbased matching, our approach results in entire control polygons that retain landscape-level characteristics of treatment sites, which more accurately describes the LSLT treatment assignment mechanism.

However, our control sites did not contain better covariate balance than the wider donut regions (Fig. 5A), making sampling from the control sites similar to a donut-based approach. It is possible that the limited bias reduction in the first stage is specific to our case, and the generalizability of this two-stage approach to other contexts merits further scrutiny. Nevertheless, the dramatic differences between the 0 -stage and 1-stage indirect LULC change estimates (Fig. 6) demonstrate the importance of counterfactual-based analysis. Further, there are several instances in which the second-stage estimates differed from the first stage, indicating that the improved covariate balance achieved through the point-based analysis can have substantive implications.

The divergence of outcomes that we observed between our sites highlights the importance of a site-based approach to impact evaluation. Large-scale studies typically focus on estimating an average effect across an entire region (e.g., Davis et al. 2015). This gives important information about overall trends but may fail to represent the diversity of lived experiences. Future large-scale studies could therefore use methods of analysis that investigate both mean and variability in effects, or identify archetypical pathways toward different kinds of impacts (Magliocca et al. 2019a).

\section{CONCLUSIONS}

Our research quantifies the direct and indirect effects of LSLTs on LULC changes across a variety of socio-environmental contexts in Ethiopia. Our study makes both substantive and methodological contributions to understanding the effects of LSLTs on LULC. It thus constitutes an important step toward further understanding the implementation of LSLTs and their implications for surrounding landscapes and populations in smallholder agricultural contexts.

The LSLTs directly displaced a mix of existing LULC types, with the majority occurring in woodland-shrubland $(35 \%)$ and smallholder agricultural land (32\%). However, only $38 \%$ of the transacted area was actually developed into large-scale agriculture. This conforms with the widely observed tendency for actual levels of development to be lower than initially anticipated, possibly suggesting speculative investments or problems with financing the developments. Of the land that did transition into large-scale agriculture, the majority of this originated from smallholder agriculture $(53 \%)$, with smaller amounts originating from woodland-shrubland $(35 \%)$ and forest $(9 \%)$. The result that LSLTs have displaced large amounts of smallholder agriculture sets Ethiopia apart from other studied contexts in which the focus has been primarily on deforestation outcomes, which may miss these kinds of LULC transitions. Hence, future studies investigating LULC change in similar contexts should not solely use forest cover to assess effects.

Each LSLT targeted a unique landscape and involved different extents of large-scale conversion, leading to divergent indirect LULC change outcomes. In general, the effects on smallholder expansion were stronger than those on smallholder abandonment, with LSLTs associated with both increased and decreased smallholder expansion. Increased smallholder expansion occurred in sites with low levels of existing smallholder agriculture, as well as sites that contained high levels of existing smallholder agriculture both inside and outside the LSLT. These divergent effects demonstrate that large-scale studies focusing on the average effect may fail to reveal the true range of lived experiences. In reality, individual land deals are unique; hence, a site-level focus is appropriate and it may be difficult to generalize or predict outcomes in different contexts.

To estimate indirect LULC change we employed a novel, twostage treatment-control comparison procedure. We first generated counterfactual control sites to adjust for bias in the treatmentassignment mechanism, i.e., the location of the LSLT, which is influenced by site-level conditions. Second, we reweighted points sampled from within these control sites to adjust for situationlevel conditions driving LULC change outcomes. Together, this procedure produced more robust counterfactual observations for causal effect estimation than a non-comparative land-use change study or a single-stage matching procedure. Further, because appropriate wall-to-wall LULC data do not exist in this context, it required significantly less LULC data classification than the standard, donut-based approach. Our results reveal discrepancies between the indirect LULC change estimates calculated with and 
without the matching procedure, demonstrating its added value and highlighting the potential for traditional land change assessments, i.e., without a counterfactual, to mis-estimate LULC changes. Future studies seeking to estimate land cover changes could therefore adopt treatment-control designs similar to ours.

Responses to this article can be read online at: https://www.ecologyandsociety.org/issues/responses. php/12825

\section{Acknowledgments:}

This work is supported by funding from the NASA Land Cover Land Use Change Program (\#NNX15AD40G) and NSF Coupled Natural and Human Systems Program (DEB-1617364). We would like to thank Chuying Lu, Stephanie Miller, and undergraduate research assistants at the University of Michigan for their substantial work to classify satellite imagery. We thank Alemayehu Ayana for his coordination of work in the field. Finally, the authors are grateful to the anonymous reviewers, whose insightful comments helped to improve the clarity of the article.

\section{Data Availability:}

The data and code that support the findings of this study are openly available at The Open Science Framework at https:/ldx.doi. org/10.17605/OSF.IO/P4EUA

\section{LITERATURE CITED}

Agrawal, A., D. G. Brown, and J. A. Sullivan. 2019. Are global land grabs ticking socio-environmental bombs or just inefficient investments? One Earth 1(2):159-162. https://doi.org/10.1016/j. oneear.2019.10.004

Ali, D., K. Deininger, and A. Harris. 2015. Using national statistics to increase transparency of large land acquisition: evidence from Ethiopia. The World Bank, Washington, D.C., USA. https://doi.org/10.1596/1813-9450-7342

Ali, D., K. Deininger, and A. Harris. 2019. Does large farm establishment create benefits for neighboring smallholders? Evidence from Ethiopia. Land Economics 95(1):71-90. https:// doi.org/10.3368/le.95.1.71

Austin, P. C. 2009. Balance diagnostics for comparing the distribution of baseline covariates between treatment groups in propensity-score matched samples. Statistics in Medicine 28 (25):3083-3107. https://doi.org/10.1002/sim.3697

Ben Yishay, A., B. Parks, D. Runfola, and R. Trichler. 2016. Forest cover impacts of Chinese development projects in ecologically sensitive areas. AidData Working Paper \#32. William \& Mary, Williamsburg, Virginia.

Blackman, A. 2013. Evaluating forest conservation policies in developing countries using remote sensing data: an introduction and practical guide. Forest Policy and Economics 34:1-16. https:// doi.org/10.1016/j.forpol.2013.04.006
Busso, M., J. DiNardo, and J. McCrary. 2014. New evidence on the finite sample properties of propensity score reweighting and matching estimators. Review of Economics and Statistics 96 (5):885-897. https://doi.org/10.1162/REST_a_00431

Carlson, K. M., L. M. Curran, D. Ratnasari, A. M. Pittman, B. S. Soares-Filho, G. P. Asner, S. N. Trigg, D. A. Gaveau, D. Lawrence, and H. O. Rodrigues. 2012. Committed carbon emissions, deforestation, and community land conversion from oil palm plantation expansion in West Kalimantan, Indonesia. Proceedings of the National Academy of Sciences of the United States of America 109(19):7559-7564. https://doi.org/10.1073/ pnas. 1200452109

Coomes, O. T., Y. Takasaki, and J. M. Rhemtulla. 2016. Forests as landscapes of social inequality: tropical forest cover and land distribution among shifting cultivators. Ecology and Society 21 (3):20. https://doi.org/10.5751/ES-08684-210320

Cotula, L. 2009. Land grab or development opportunity? Agricultural investment and international land deals in Africa. International Institute for Environment and Development, London, UK, Food and Agriculture Organization, and International Fund for Agricultural Development, Rome, Italy.

Davis, K. F., H. I. Koo, J. Dell'Angelo, P. D’Odorico, L. Estes, L. J. Kehoe, M. Kharratzadeh, T. Kuemmerle, D. Machava, A. de J. R. Pais, N. Ribeiro, M. C. Rulli, and M. Tatlhego. 2020. Tropical forest loss enhanced by large-scale land acquisitions. Nature Geoscience 13(7):482-488. https://doi.org/10.1038/s41561-020-0592-3

Davis, K. F., K. Yu, M. C. Rulli, L. Pichdara, and P. D’Odorico. 2015. Accelerated deforestation driven by large-scale land acquisitions in Cambodia. Nature Geoscience 8:772-775. https:// doi.org/10.1038/ngeo 2540

De Schutter, O. 2011. The green rush: the global race for farmland and the rights of land users. Harvard International Law Journal 52:503.

Debonne, N., J. van Vliet, G. Metternicht, and P. Verburg. 2021. Agency shifts in agricultural land governance and their implications for land degradation neutrality. Global Environmental Change 66:102221. https://doi.org/10.1016/j.gloenvcha.2020.102221

Deininger, K., and D. Byerlee. 2011. Rising global interest in farmland: can it yield sustainable and equitable benefits? The World Bank, Washington, D.C., USA. https://doi. org/10.1596/978-0-8213-8591-3

Dell'Angelo, J., P. D’Odorico, M. C. Rulli, and P. Marchand. 2017. The tragedy of the grabbed commons: coercion and dispossession in the global land rush. World Development 92:1-12. https://doi. org/10.1016/j.worlddev.2016.11.005

Diamond, A., and J. S. Sekhon. 2013. Genetic matching for estimating causal effects: a general multivariate matching method for achieving balance in observational studies. Review of Economics and Statistics 95(3):932-945. https://doi.org/10.1162/ REST_a_00318

D’Odorico, P., M. C. Rulli, J. Dell'Angelo, and K. F. Davis. 2017. New frontiers of land and water commodification: socioenvironmental controversies of large-scale land acquisitions. 
Land Degradation \& Development 28(7):2234-2244. https://doi. org/10.1002/ldr.2750

Eckert, S., M. Giger, and P. Messerli. 2016. Contextualizing localscale point sample data using global-scale spatial datasets: lessons learnt from the analysis of large-scale land acquisitions. Applied Geography 68:84-94. https://doi.org/10.1016/j.apgeog.2016.01.008

Edelman, M. 2013. Messy hectares: questions about the epistemology of land grabbing data. Journal of Peasant Studies 40(3):485-501. https://doi.org/10.1080/03066150.2013.801340

Ferraro, P. J., and M. M. Hanauer. 2015. Through what mechanisms do protected areas affect environmental and social outcomes? Philosophical Transactions of the Royal Society of London. Series B, Biological Sciences 370(1681). https://doi. org/10.1098/rstb.2014.0267

Fox, J., T. Nghiem, H. Kimkong, K. Hurni, and I. G. Baird. 2018. Large-scale land concessions, migration, and land use: the paradox of industrial estates in the Red River Delta of Vietnam and rubber plantations of northeast Cambodia. Land 7(2):77. https://doi.org/10.3390/land7020077

Griffith, D. A. 1987. Spatial autocorrelation: a primer. Association of American Geographers, Washington, D.C., USA.

Hainmueller, J. 2012. Entropy balancing for causal effects: a multivariate reweighting method to produce balanced samples in observational studies. Political Analysis 20(1):25-46. https://doi. org/10.1093/pan/mpr025

Hajjar, R., A. N. Ayana, R. Rutt, O. Hinde, C. Liao, S. Keene, S. Bandiaky-Badji, and A. Agrawal. 2019. Capital, labor, and gender: the consequences of large-scale land transactions on household labor allocation. Journal of Peasant Studies 47 (3):566-588. https://doi.org/10.1080/03066150.2019.1602520

Hansen, M. C., P. V. Potapov, R. Moore, M. Hancher, S. A. Turubanova, A. Tyukavina, D. Thau, S. V. Stehman, S. J. Goetz, T. R. Loveland, A. Kommareddy, A. Egorov, L. Chini, C. O. Justice, and J. R. G. Townshend. 2013. High-resolution global maps of 21 st-century forest cover change. Science 342 (6160):850-853. https://doi.org/10.1126/science.1244693

Jiao, X., C. Smith-Hall, and I. Theilade. 2015. Rural household incomes and land grabbing in Cambodia. Land Use Policy 48:317-328. https://doi.org/10.1016/j.landusepol.2015.06.008

Keeley, J., W. M. Seide, A. Eid, and A. L. Kidewa. 2014. Largescale land deals in Ethiopia: scale, trends, features and outcomes to date. International Institute for Environment and Development, London, UK.

Lambin, E. F., and P. Meyfroidt. 2011. Global land use change, economic globalization, and the looming land scarcity. Proceedings of the National Academy of Sciences 108 (9):3465-3472. https://doi.org/10.1073/pnas.1100480108

Lambin, E. F., B. L. Turner, H. J. Geist, S. B. Agbola, A. Angelsen, J. W. Bruce, O. T. Coomes, R. Dirzo, G. Fischer, C. Folke, P. S. George, K. Homewood, J. Imbernon, R. Leemans, X. Li, E. F. Moran, M. Mortimore, P. S. Ramakrishnan, J. F. Richards, H. Skånes, W. Steffen, G. D. Stone, U. Svedin, T. A. Veldkamp, C. Vogel, and J. Xu. 2001. The causes of land-use and land-cover change: moving beyond the myths. Global Environmental Change 11(4):261-269. https://doi.org/10.1016/S0959-3780(01) $\underline{00007-3}$

Liao, C., S. Jung, D. G. Brown, and A. Agrawal. 2020. Spatial patterns of large-scale land transactions and their potential socioenvironmental outcomes in Cambodia, Ethiopia, Liberia, and Peru. Land Degradation \& Development 31(10):1241-1251. https://doi.org/10.1002/ldr.3544

Magliocca, N. R., Q. Van Khuc, A. de Bremond, and E. A. Ellicott. 2019b. Direct and indirect land-use change caused by large-scale land acquisitions in Cambodia. Environmental Research Letters 15(2). https://doi.org/10.1088/1748-9326/ ab6397

Magliocca, N. R., Q. Van Khuc, E. A. Ellicott, and A. de Bremond. 2019a. Archetypical pathways of direct and indirect land-use change caused by Cambodia's economic land concessions. Ecology and Society 24(2):25. https://doi. org/10.5751/ES-10954-240225

Messerli, P., C. Bader, C. Hett, M. Epprecht, and A. Heinimann. 2015. Towards a spatial understanding of trade-offs in sustainable development: a meso-scale analysis of the nexus between land use, poverty, and environment in the Lao PDR. PLoS ONE 10 (7):e0133418. https://doi.org/10.1371/journal.pone.0133418

Messerli, P., M. Giger, M. B. Dwyer, T. Breu, and S. Eckert. 2014. The geography of large-scale land acquisitions: analysing socioecological patterns of target contexts in the Global South. Applied Geography 53:449-459. https://doi.org/10.1016/j. apgeog.2014.07.005

Meyfroidt, P., R. Roy Chowdhury, A. de Bremond, E. C. Ellis, K.-H. Erb, T. Filatova, R. D. Garrett, J. M. Grove, A. Heinimann, T. Kuemmerle, C. A. Kull, E. F. Lambin, Y. Landon, Y. le Polain de Waroux, P. Messerli, D. Müller, J. Ø. Nielsen, G. D. Peterson, V. Rodriguez García, M. Schlüter, B. L. Turner, and P. H. Verburg. 2018. Middle-range theories of land system change. Global Environmental Change 53:52-67. https://doi.org/10.1016/j. gloenvcha.2018.08.006

Moreda, T. 2015. Listening to their silence? The political reaction of affected communities to large-scale land acquisitions: insights from Ethiopia. Journal of Peasant Studies 42(3-4):517-539. https://doi.org/10.1080/03066150.2014.993621

Nalepa, R. A., A. G. Short Gianotti, and D. M. Bauer. 2017. Marginal land and the global land rush: a spatial exploration of contested lands and state-directed development in contemporary Ethiopia. Geoforum 82:237-251. https://doi.org/10.1016/j. geoforum.2016.10.008

Nanhthavong, V., C. Oberlack, C. Hett, P. Messerli, and M. Epprecht. 2021. Pathways to human well-being in the context of land acquisitions in Lao PDR. Global Environmental Change 68:102252. https://doi.org/10.1016/j.gloenvcha.2021.102252

Nolte, C., A. Agrawal, K. M. Silvius, and B. S. Soares-Filho. 2013. Governance regime and location influence avoided deforestation success of protected areas in the Brazilian Amazon. Proceedings of the National Academy of Sciences 110(13):4956-4961. https:// doi.org/10.1073/pnas. 1214786110 
Oberlack, C., L. Tejada, P. Messerli, S. Rist, and M. Giger. 2016. Sustainable livelihoods in the global land rush? Archetypes of livelihood vulnerability and sustainability potentials. Global Environmental Change 41:153-171. https://doi.org/10.1016/j. gloenvcha.2016.10.001

Rahmato, D. 2011. Land to investors: large-scale land transfers in Ethiopia. African Books Collective, Oxford, UK.

Rasmussen, L. V., C. Watkins, and A. Agrawal. 2017. Forest contributions to livelihoods in changing agriculture-forest landscapes. Forest Policy and Economics 84:1-8. https://doi. org/10.1016/j.forpol.2017.04.010

Rulli, M. C., and P. D’Odorico. 2014. Food appropriation through large scale land acquisitions. Environmental Research Letters 9 (6):064030. https://doi.org/10.1088/1748-9326/9/6/064030

Schoneveld, G. C. 2011. The anatomy of large-scale farmland acquisitions in sub-Saharan Africa. CIFOR Working Paper (85)., CIFOR, Bogor, Indonesia.

Shennan, C. 2008. Biotic interactions, ecological knowledge and agriculture. Philosophical Transactions of the Royal Society B: Biological Sciences 363(1492):717-739. https://doi.org/10.1098/ $\underline{\text { rstb. } 2007.2180}$

Shete, M., and M. Rutten. 2015. Impacts of large-scale farming on local communities' food security and income levels - empirical evidence from Oromia Region, Ethiopia. Land Use Policy 47:282-292. https://doi.org/10.1016/j.landusepol.2015.01.034

Shete, M., M. Rutten, G. C. Schoneveld, and E. Zewude. 2016. Land-use changes by large-scale plantations and their effects on soil organic carbon, micronutrients and bulk density: empirical evidence from Ethiopia. Agriculture and Human Values 33 (3):689-704. https://doi.org/10.1007/s10460-015-9664-1

Sweeney, S., T. Ruseva, L. Estes, and T. Evans. 2015. Mapping cropland in smallholder-dominated savannas: integrating remote sensing techniques and probabilistic modeling. Remote Sensing 7(11):15295-15317. https://doi.org/10.3390/rs71115295

Teklemariam, D., H. Azadi, J. Nyssen, M. Haile, and F. Witlox. 2016. How sustainable is transnational farmland acquisition in Ethiopia? Lessons learned from the Benishangul-Gumuz Region. Sustainability 8(3):213. https://doi.org/10.3390/su8030213

Thornton, P. K., and M. Herrero. 2015. Adapting to climate change in the mixed crop and livestock farming systems in subSaharan Africa. Nature Climate Change 5(9):830-836. https:// doi.org/10.1038/nclimate2754

Vosti, S. A., and T. A. Reardon. 1997. Sustainability, growth, and poverty alleviation: a policy and agroecological perspective. International Food Policy Research Institute, Washington, D.C., USA.

Wendimu, M. A., A. Henningsen, and P. Gibbon. 2016. Sugarcane outgrowers in Ethiopia: "forced" to remain poor? World Development 83:84-97. https://doi.org/10.1016/j.worlddev.2016.03.002

Zaehringer, J. G., A. Atumane, S. Berger, and S. Eckert. 2018. Large-scale agricultural investments trigger direct and indirect land use change: new evidence from the Nacala corridor,
Mozambique. Journal of Land Use Science 13(3):325-343. https://doi.org/10.1080/1747423X.2018.1519605 
Appendix 1. LSLT Site Information

Table A1.1: LSLT characteristics.

\begin{tabular}{|l|l|l|l|l|l|l|l|}
\hline Site Code & Region & Farm ID & Ownership & Start & Size (ha) & LULC before & LULC after \\
\hline BG3 & Beneshangul Gumuz & Asosa & Germany & 2008 & 1000 & Forests & Maize \\
\hline BG4 & Beneshangul Gumuz & Bambasi & Domestic & 2012 & 500 & Forests & Soybean \\
\hline GM1 & Gambella & Saudi Star 1 & Saudi Arabia & 2005 & 3000 & State Farm & Rice \\
\hline GM5 & Gambella & Nuer & Domestic & 2013 & 800 & Forests & Mung bean, cotton \\
\hline OR1 & Oromiya & Adama & Domestic & 2012 & 1200 & Smallholder & Sugarcane \\
\hline OR2 & Oromiya & Ziway & USA & 2012 & 500 & State ranch & Maize \\
\hline OR4 & Oromiya & Sibu Sire & India & 2003 & 3500 & State ranch & Sugarcane, maize \\
\hline OR5 & Oromiya & Gutin & Domestic & 2005 & 700 & Forests & Maize \\
\hline
\end{tabular}


Appendix 2. LULC Imagery and Classification Details

\section{A2.1. Imagery Availability}

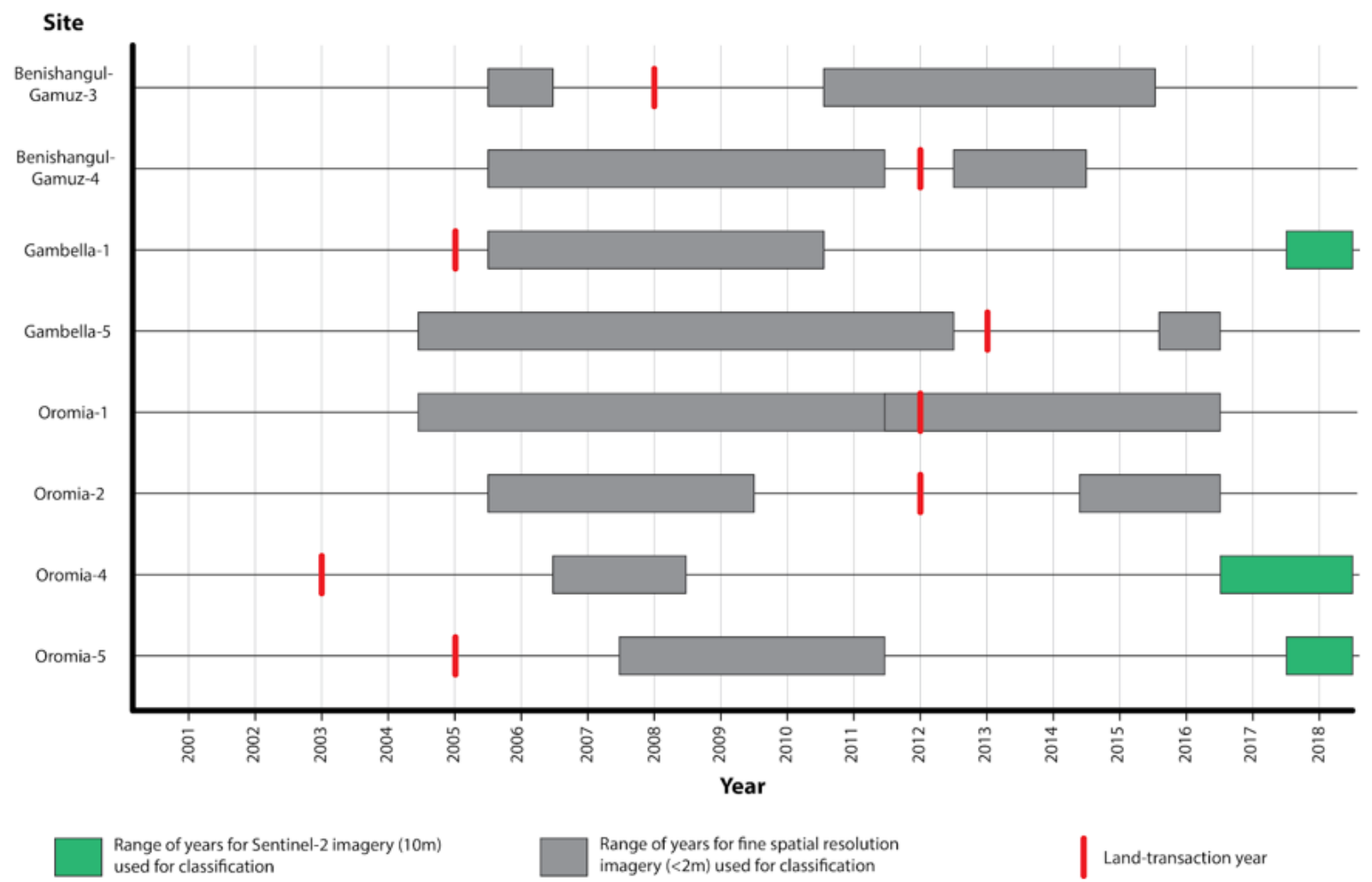

Fig. A2.1: Dates of satellite imagery in relation to the LSLT implementation years 


\section{A2.2. LULC Classification Process}

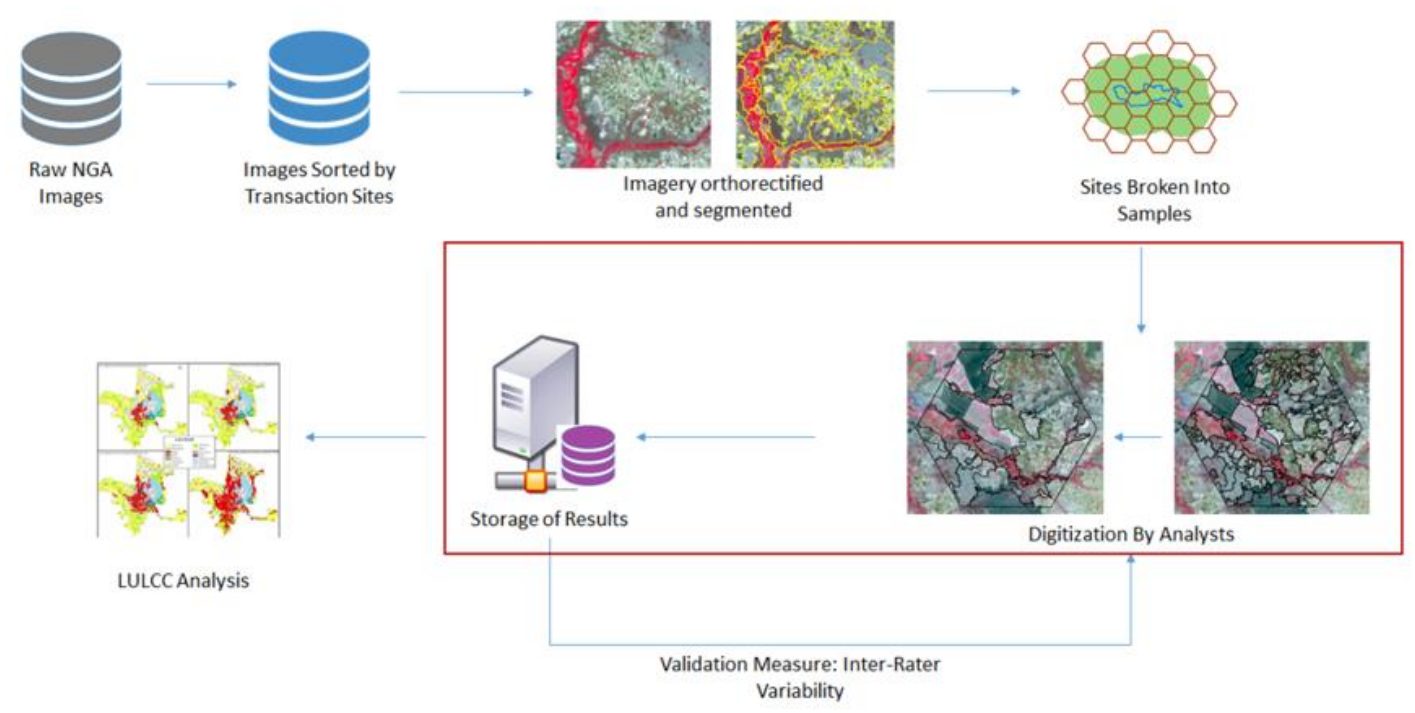

Fig. A2.2: Image classification pipeline.

1. Raw Images: 30,643 images, dating from 2004-201, obtained from: IKONOS (1-4m); GeoEye-1 (0.5 - 2m); WorldView-1, 2, and 3 (0.3-2m); and Sentinel-2 (10m)

2. Sort by Site: sorted to each site (BG3, BG4, GM1, GM2, OR1, OR2, OR4, and OR5), then by Treatment or Control, and then by Pre- or Post- transaction date. Resulting in 4 sets of images per site (e.g. BG3-Treatment-Pre, BG3-Treatment-Post, BG3-Control-Pre, BG3-Control-Post)

3. Segmentation - an object based classification was used to partition the landscape into polygons by distinct spectral and textural characteristics

4. Data Organization - to help keep assign and keep track of analysts' progress, a hexagon grid (each hex $=15 \mathrm{~km} 2$ ) was overlaid on each site. A geodatabase was created for each site as well.

5. ArcGIS: In Arc, analysts edited the attribute tables to assign a LULC to each polygon created in the Segmentation (3) process. If adjacent polygons appeared to be the same they were combined using the Merge tool. After an entire site was completed, any polygons that were split when gridding the sites into hexagons were merged if of the same LULC.

6. Analyst Classification - User and Producer's Accuracy was used to evaluate the agreement between raters of each LULC. Each rater was asked to classify the same set of three hexagons (that each contained all LULC types/choices). Then, the Tabulate Intersection tool was used to identify areas of disagreement in LULC assignment between raters. User's and Producer's matrices were computed in Excel to find percent agreement between individual raters and individual classes (Appendix D)

7. Classified Site - For each site, Treatment and Control, Pre- and Post- classifications were overlaid and the Tabulate Intersection tool was used again to find the transition of LULC types from before and after a transaction date. 


\section{A2.3: LULC Examples}

Descriptions and examples were used to train analysts. We note that the examples presented here are from Tanzania (another country in our project), but they demonstrate the relevant LULC characteristics.

Smallholder Agriculture - cultivated areas (<10ha) with a mosaic of different subsistence crops (primarily cereals), fallow area, and cycle of crop maturity; some settlements and sparse tree cover.

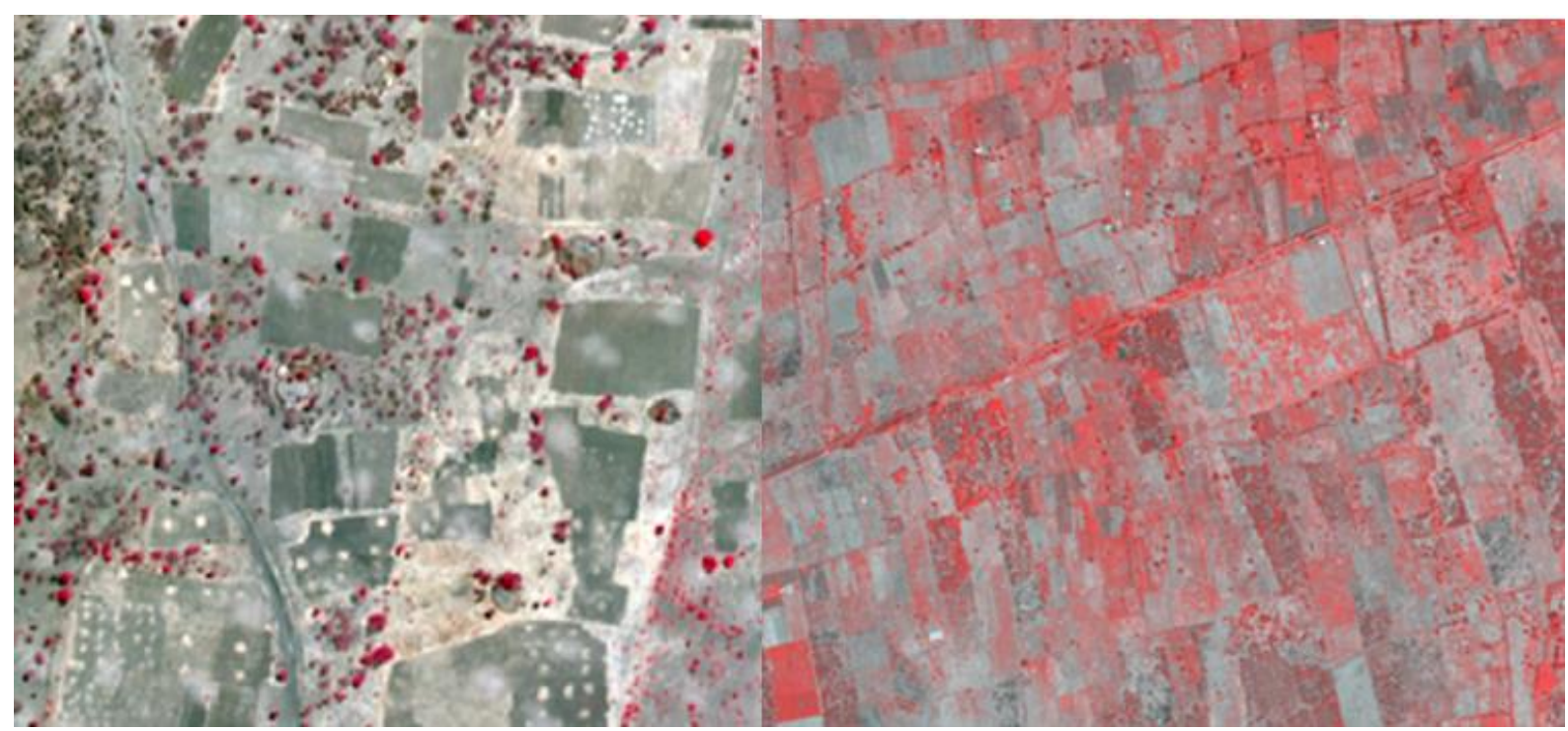

Intensive Agriculture - cultivated fields (>10ha) with vegetation pattern indicating uniform planting (monocrop) and harvest cycles; may include tree crops and is clearly visible from satellite imagery.

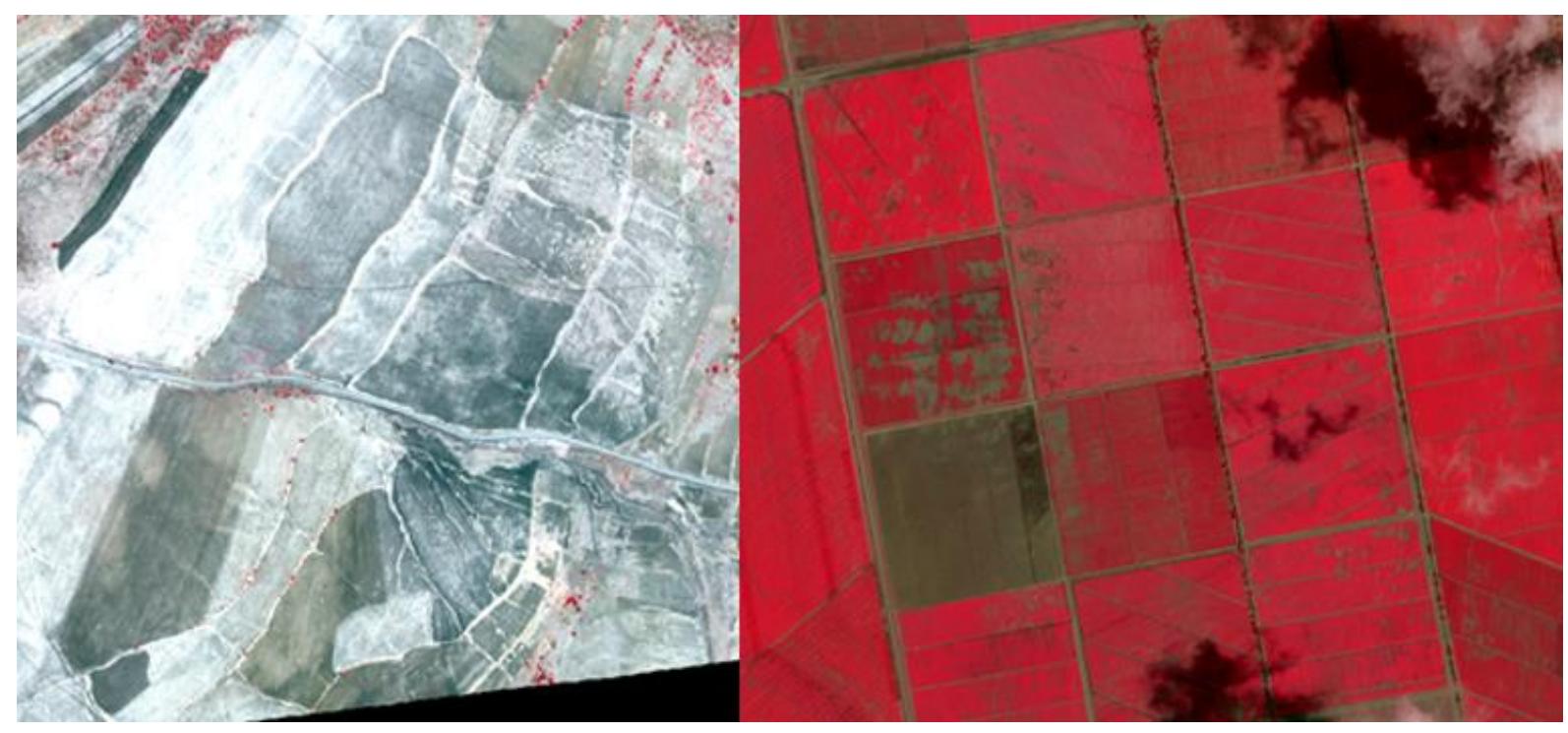


Forest - Densely forested area with 70-100\% closed canopy cover

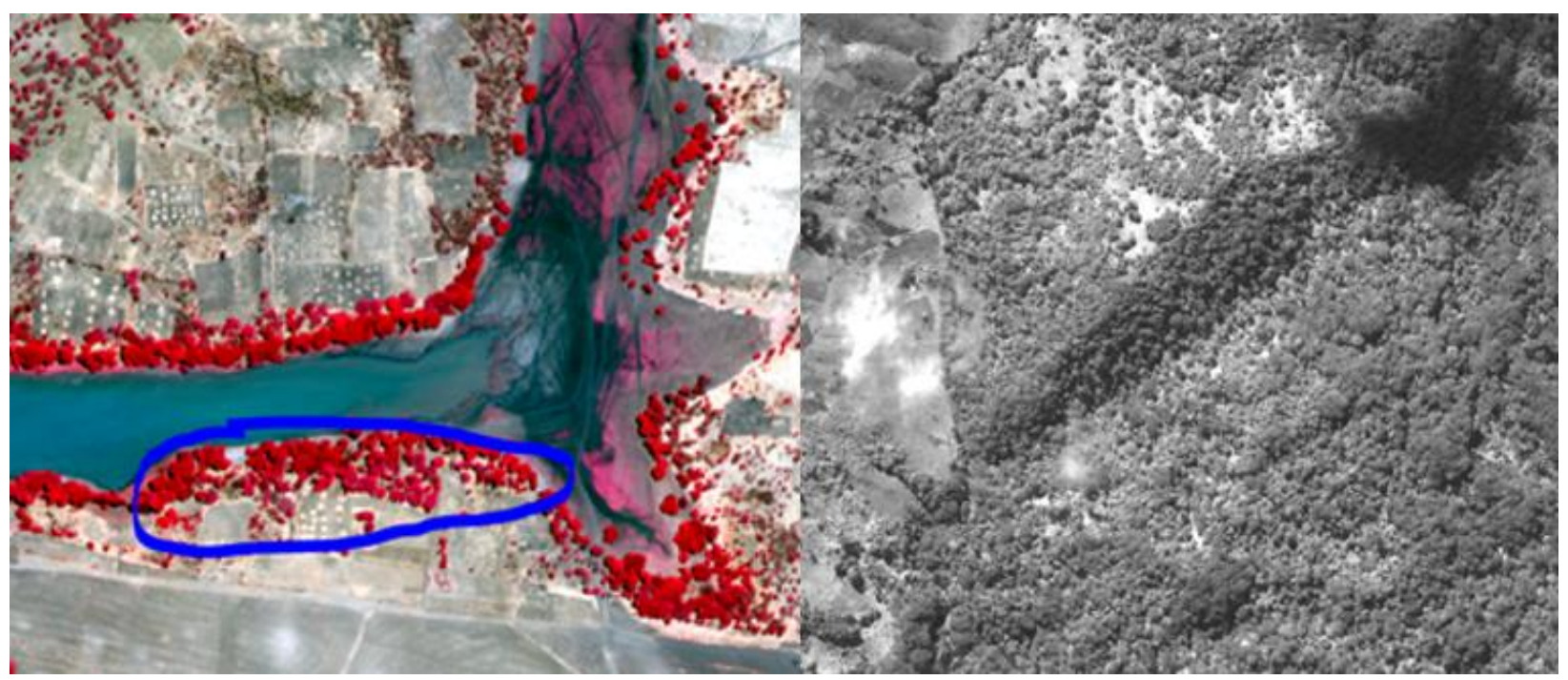

Woodland/Shrubland - mixed area of small trees, short bushes, shrubs and open grassland; $10-70 \%$ ground coverage, small trees $(<10 \%)$

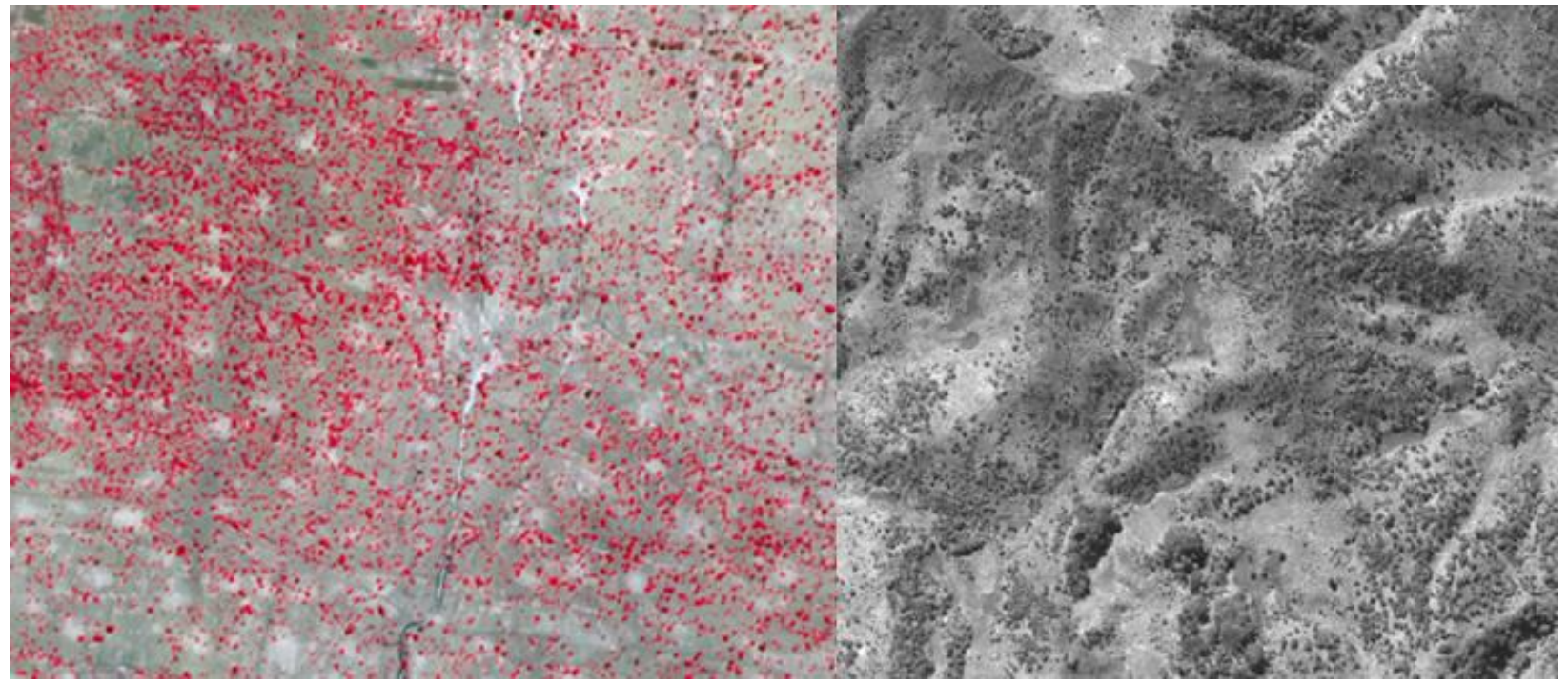


Bare/Exposed Soil - land with very sparse grass or completely no vegetation cover.

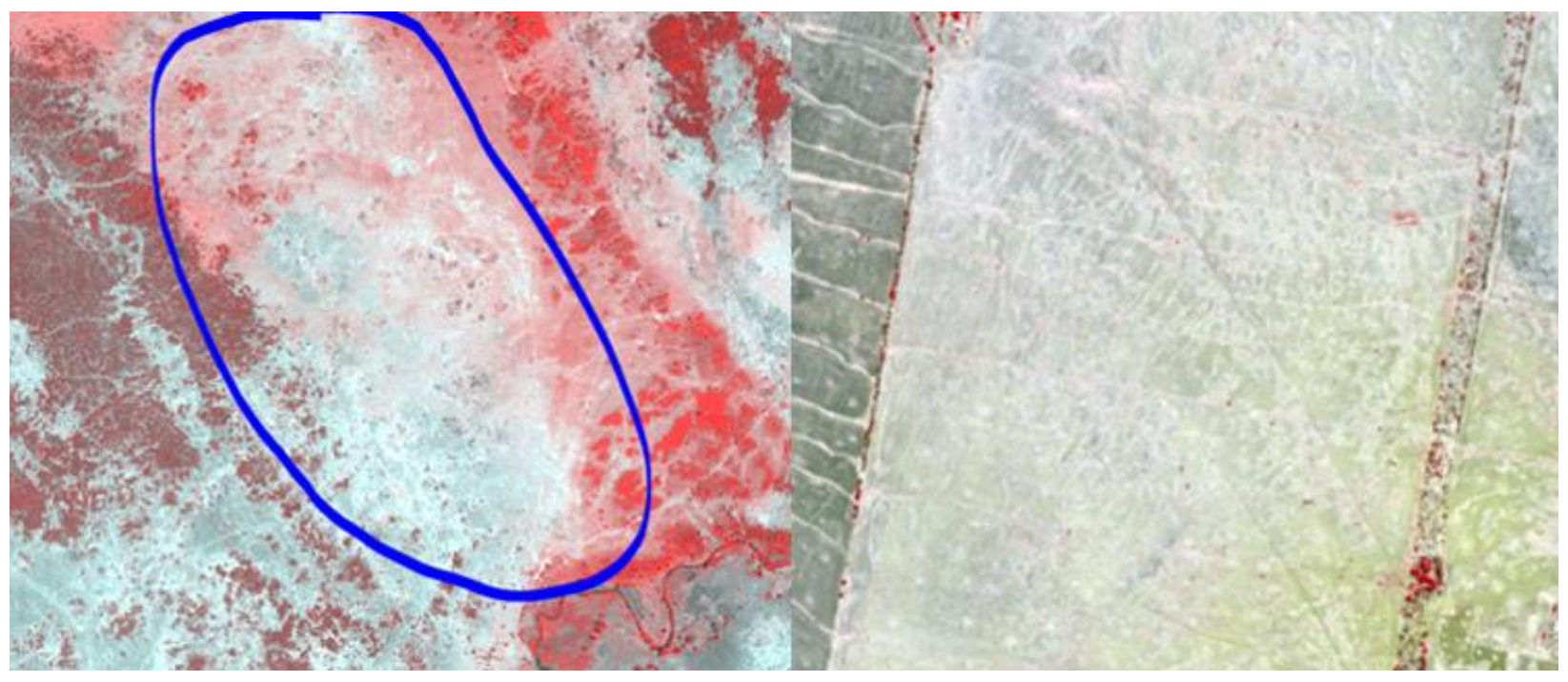

Rural Settlement - natural and impermeable surfaces, including roads and dense housing.

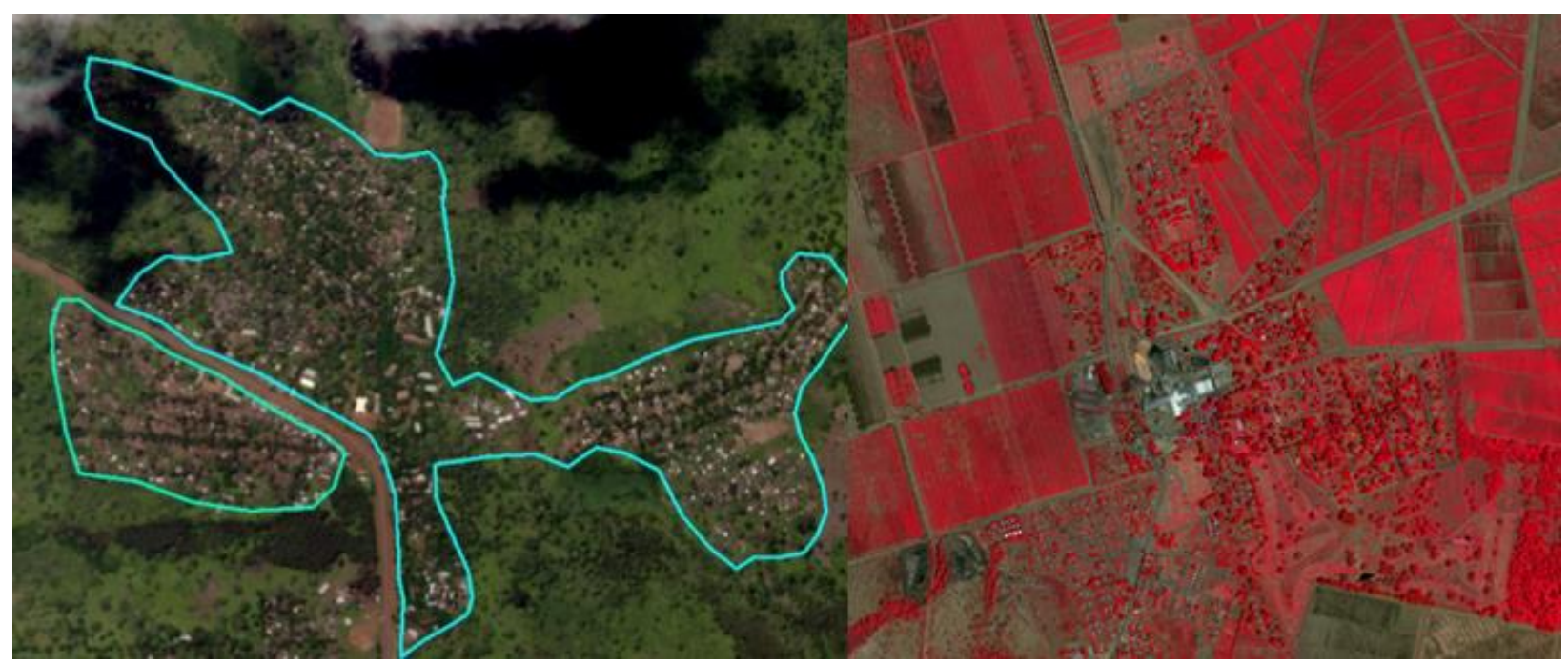


Development - major roads and urban or industrial infrastructure with a minimum mapping unit of 30 meters.
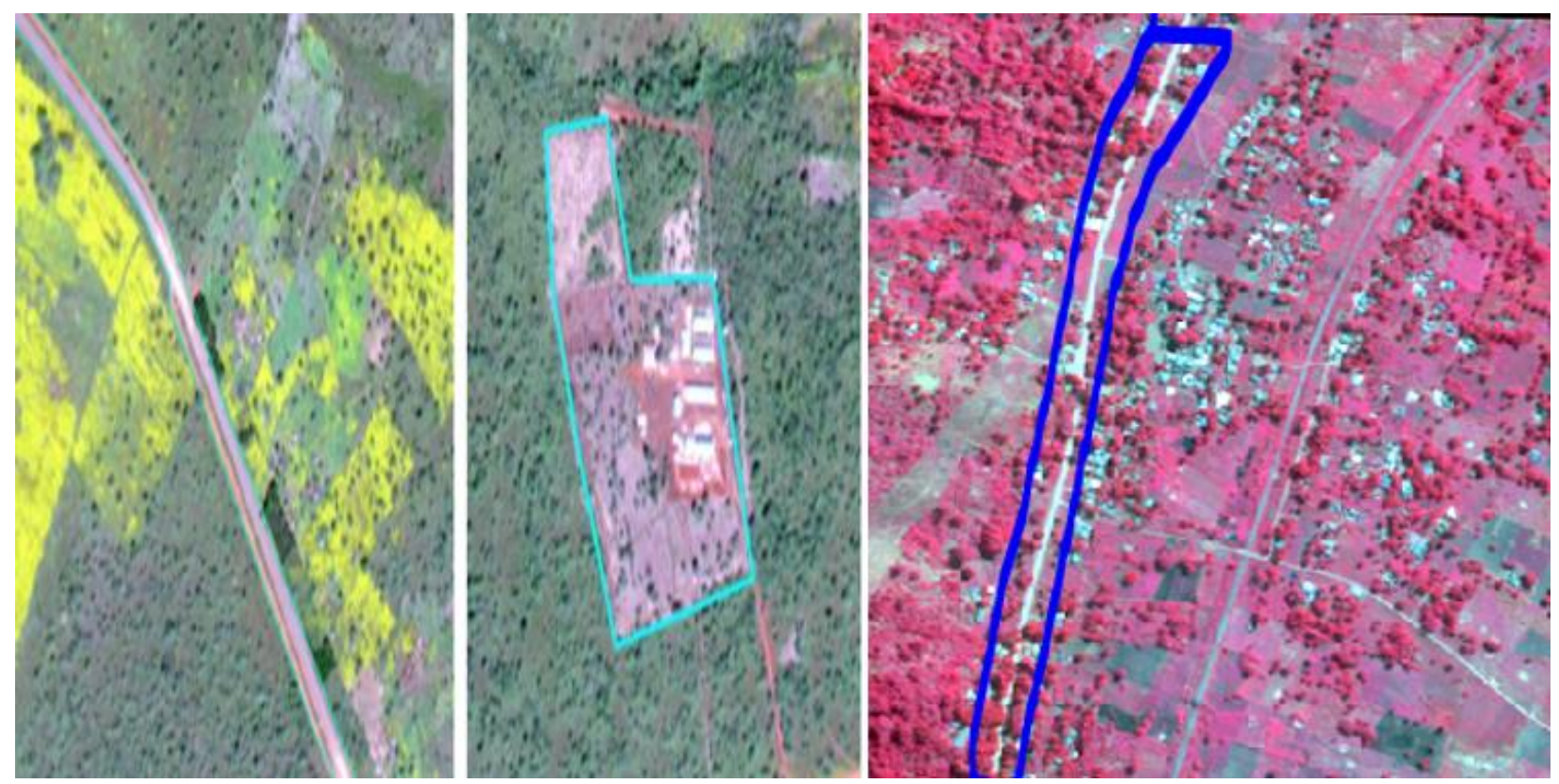

Water - natural and artificial water bodies; river, lakes and reservoirs.

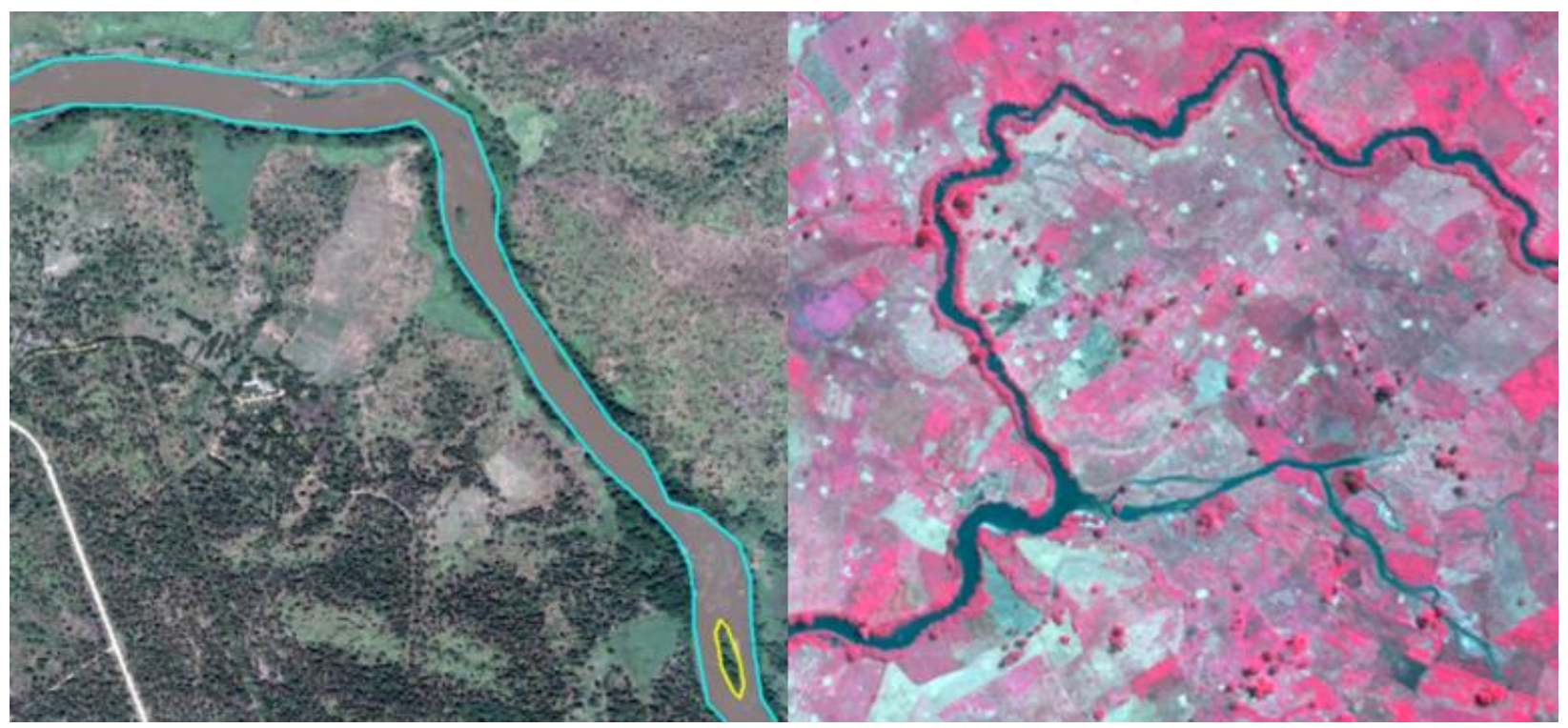


Wetland - swampy and waterlogged in the wet season (June-August), dry in the dry season (December February)

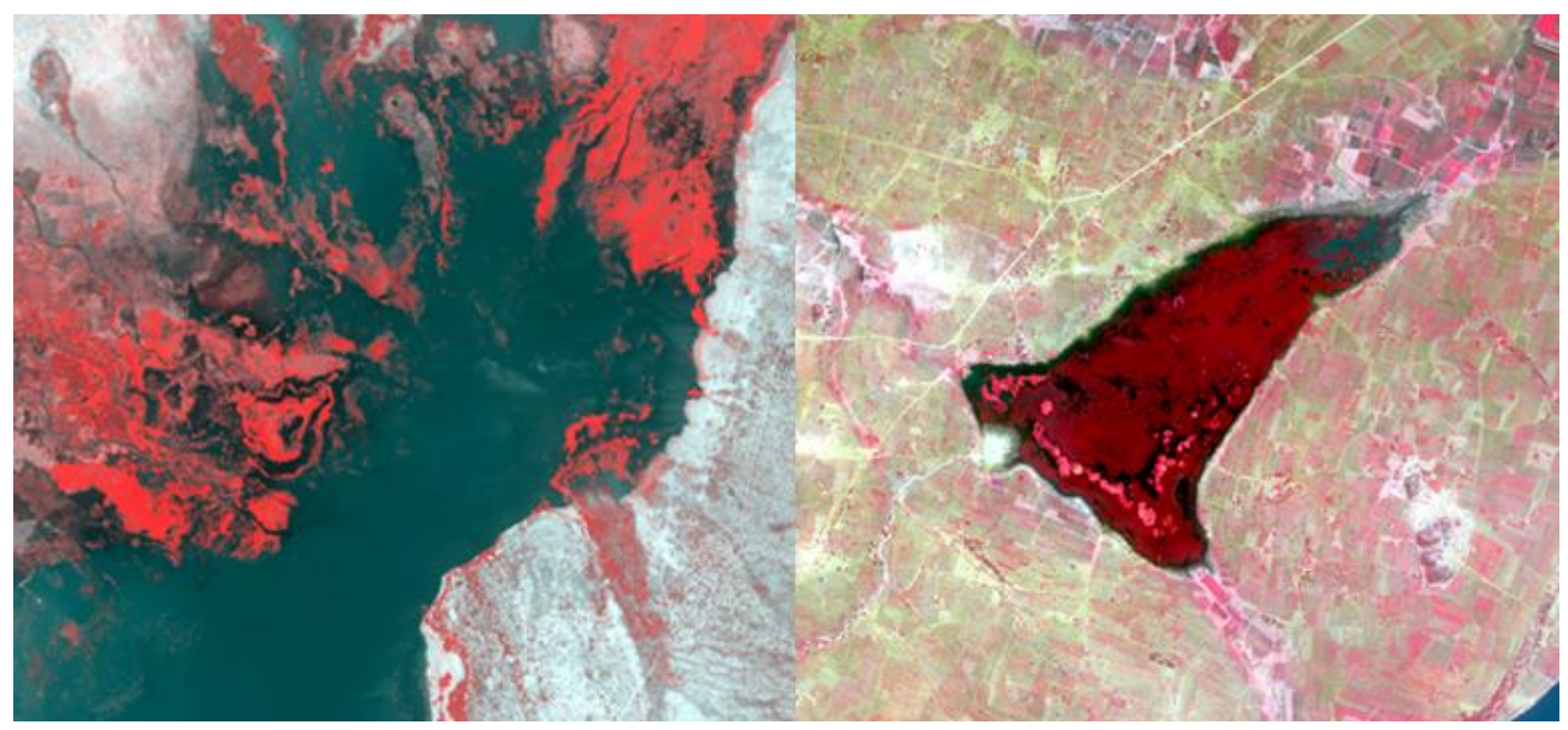




\section{A2.4. Inter-Rater Reliability}

We conducted an inter-rater reliability test to account for work completed by multiple analysts. We divided the sites into sets of $15 \mathrm{~km}^{2}$ hexagons and asked each analyst to independently classify the same three areas to compare their LULC decisions. User's and Producer's Accuracy was calculated to assess agreement between individual raters and each LULC. Agreement between analysts ranged from $53-69 \%$.

\section{Table A2.1: Rater agreement}

\begin{tabular}{|l|l|}
\hline Rater & Percent agreement \\
\hline XW & 52.7 \\
\hline PN & 56.4 \\
\hline NC & 61.2 \\
\hline DW & 59.9 \\
\hline CL & 60.0 \\
\hline AB & 69.4 \\
\hline
\end{tabular}

Table A2.2: Inter-rater class agreement

\begin{tabular}{|c|c|c|c|}
\hline LULC Class & IRR $(\%)$ & Aggregated class & IRR $(\%)$ \\
\hline Smallholder agriculture & 80.7 & \multirow{2}{*}{ Smallholder } & \multirow[t]{2}{*}{80.7} \\
\hline Rural settlement & $\mathrm{n} / \mathrm{a}$ & & \\
\hline Large-scale agriculture & 55.4 & Large-scale agriculture & 55.4 \\
\hline Forest & 73.9 & Forest & 73.9 \\
\hline Woodland/ shrubland & 78.9 & Woodland/ shrubland & 78.9 \\
\hline Bare/exposed soil & 19.6 & Bare/exposed soil & 19.6 \\
\hline Development & 81.7 & \multirow{3}{*}{ Other } & \multirow[t]{3}{*}{36.9} \\
\hline Water & 4.6 & & \\
\hline Wetland & $\mathrm{n} / \mathrm{a}$ & & \\
\hline
\end{tabular}




\section{Appendix 3. Covariate Data Sources}

Table A3.1: Sources and brief justification for covariate data. Where possible, covariate information was drawn from data that pre-dated the implementation of the LSLTs.

\begin{tabular}{|c|c|c|c|c|}
\hline Covariate & $\begin{array}{l}\text { Resolution } \\
\text { (m) }\end{array}$ & Year & Source & Notes / justification \\
\hline Elevation & 30 & $\mathrm{n} / \mathrm{a}$ & SRTM $30 \mathrm{~m}^{1}$ & $\begin{array}{l}\text { Elevation varies widely over Ethiopia and is associated with } \\
\text { climate and agricultural suitability and productivity. As such, } \\
\text { elevation may influence both LULCC and the location of a land } \\
\text { transaction. For example, areas with more favorable climatic } \\
\text { conditions (proxied by elevation) are both more likely to be } \\
\text { converted into smallholder agriculture and sold to an investor } \\
\text { (LSLT). }\end{array}$ \\
\hline Slope & 30 & $\mathrm{n} / \mathrm{a}$ & SRTM $30 \mathrm{~m}^{1}$ & $\begin{array}{l}\text { Areas of low slope are more suitable for agriculture, so are } \\
\text { more likely to be developed for agriculture, whether as a part } \\
\text { of an LSLT or not. }\end{array}$ \\
\hline Soil productivity & 250 & $\mathrm{n} / \mathrm{a}$ & Schaetzl et al 2012 & $\begin{array}{l}\text { Similar to above, areas of high potential productivity are more } \\
\text { likely to be developed for agriculture. } \\
\text { Method: Soil Productivity Index introduced by Schaetzl et al } \\
\text { (2012). This methodology was introduced for the United } \\
\text { States and was simplified to apply to data available for } \\
\text { Ethiopia. Values range from } 1 \text { to } 18 \text { with higher values } \\
\text { representing high productivity. }\end{array}$ \\
\hline Population density & 100 & 2010 & $\begin{array}{l}\text { AfriPop (Linard et al. } \\
\text { 2012) }\end{array}$ & $\begin{array}{l}\text { Population density can influence LULCC (e.g., population } \\
\text { pressure can lead to agricultural expansion) as well as the } \\
\text { selection of sites for transaction (Messerli et al., 2014). }\end{array}$ \\
\hline Forest cover & 30 & 2010 & GlobCover $2009^{2}$ & $\begin{array}{l}\text { Land transactions are known to occur in forested areas } \\
\text { (Dell'Angelo et al., 2017; Magliocca et al., 2019; Messerli et } \\
\text { al., 2014) and initial forest cover will also influence rates of } \\
\text { agricultural expansion and abandonment. } \\
\text { Method: Global Forest Cover "forestcover2000" and } \\
\text { "lossyear" layers were combined to create a } 2010 \text { forest cover. } \\
\text { It was assumed anywhere where loss occurred up to } 2010 \text { was } \\
\text { a complete reduction of forest cover (i.e. value of 0). Finally, } \\
\text { a } 25 \% \text { tree cover threshold was applied to provide a forest } \\
\text { cover estimate. }\end{array}$ \\
\hline Distance to road $^{3}$ & 30 & 2017 & OpenStreetMap $^{4}$ & $\begin{array}{l}\text { LSLTs often occur in more accessible regions (Messerli et al., } \\
\text { 2014). Additionally, points closer to roads are more suitable } \\
\text { for agriculture as products can be more easily transported to } \\
\text { market. } \\
\text { Method: Selected OSM roads of type: ['motorway', 'primary', } \\
\text { 'primary_link', 'residential', 'secondary', 'secondary_link', } \\
\text { 'tertiary', 'tertiary_link'] and applied Euclidean Distance. } \\
\text { Snapped to forest cover estimate. }\end{array}$ \\
\hline Night-time lights & 467 & 2015 & $\begin{array}{l}\text { VIIRS Nighttime lights } \\
\text { (Elvidge et al. 2017) }\end{array}$ & $\begin{array}{l}\text { Night-time lights are used as a proxy for development. } \\
\text { Method: VIIRS Nigthtime Lights product, avg_rad } \\
\text { (nanoWatts/cm2/sr) }\end{array}$ \\
\hline \multicolumn{5}{|c|}{$\begin{array}{l}{ }^{1} \text { (USGS, n.d.) } \\
{ }^{2} \text { http://due.esrin.esa.int/page globcover.php } \\
3 \text { We excluded this covariate in the second stage matching for BG4, GM1, OR2, and OR4 because of limited overlap in these covariate } \\
\text { distributions between the Treatment and Control sites. } \\
{ }^{4} \text { https://www.openstreetmap.org/ }\end{array}$} \\
\hline
\end{tabular}

\section{References}

Dell'Angelo, J., P. D’Odorico, M. C. Rulli, and P. Marchand. 2017. "The Tragedy of the Grabbed Commons: Coercion and Dispossession in the Global Land Rush.” World Development 92 (April): 1-12. 
Elvidge, C. D., K. Baugh, M. Zhizhin, F. C. Hsu, and T. Ghosh. 2017. "VIIRS Night-Time Lights." International Journal of Remote Sensing 38 (21): 5860-79.

Linard, C., M. Gilbert, R. W. Snow, A. M. Noor, and A. J. Tatem. 2012. "Population Distribution, Settlement Patterns and Accessibility across Africa in 2010." PloS One 7 (2): e31743.

Magliocca, N., Q. Khuc, E. Ellicott, and A. de Bremond. 2019. “Archetypical Pathways of Direct and Indirect Land-Use Change Caused by Cambodia's Economic Land Concessions." Ecology and Society 24 (2).

Messerli, P., M. Giger, M. B. Dwyer, T. Breu, and S. Eckert. 2014. "The Geography of Large-Scale Land Acquisitions: Analysing Socio-Ecological Patterns of Target Contexts in the Global South." Applied Geography 53 (September): 449-59.

Schaetzl, R. J., F. J. Krist Jr, and B. A. Miller. 2012. "A Taxonomically Based Ordinal Estimate of Soil Productivity for Landscape-Scale Analyses." Soil Science 177 (4): 288. 
Appendix 4. Additional Matching and Rebalancing Results

\section{A4.1. Control Site Selection}

The selected control sites generally a have similar levels of bias to the wider buffer regions from which they were sampled (Fig. A4.1). A notable exception, however, is in GM1, where it was not possible to find a Control site with comparable population density and elevation characteristics to the Treatment site (Fig. A4.2).

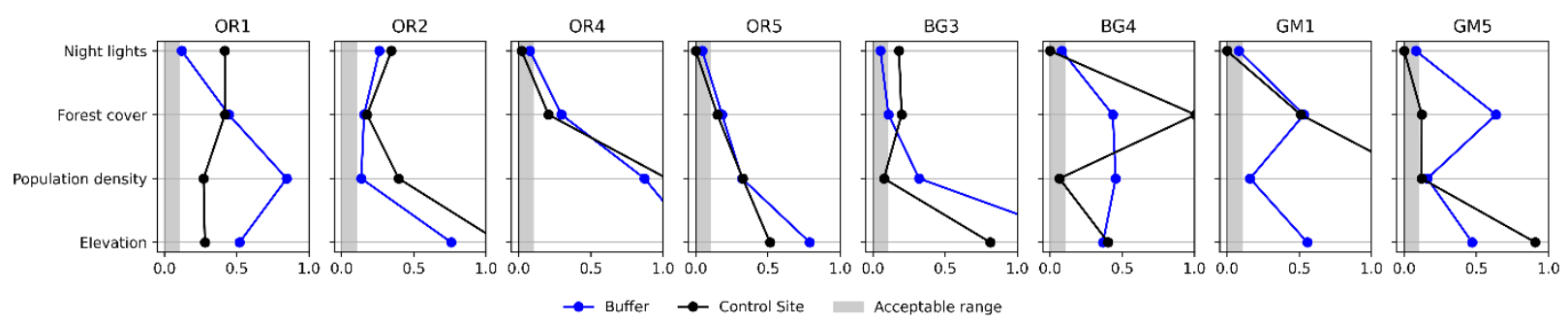

Fig. A4.1: Covariate bias for each covariate used in the first-stage Control site selection. The horizontal axes plot the absolute standardized mean difference (AMSD; Equation 1 in the main manuscript). 

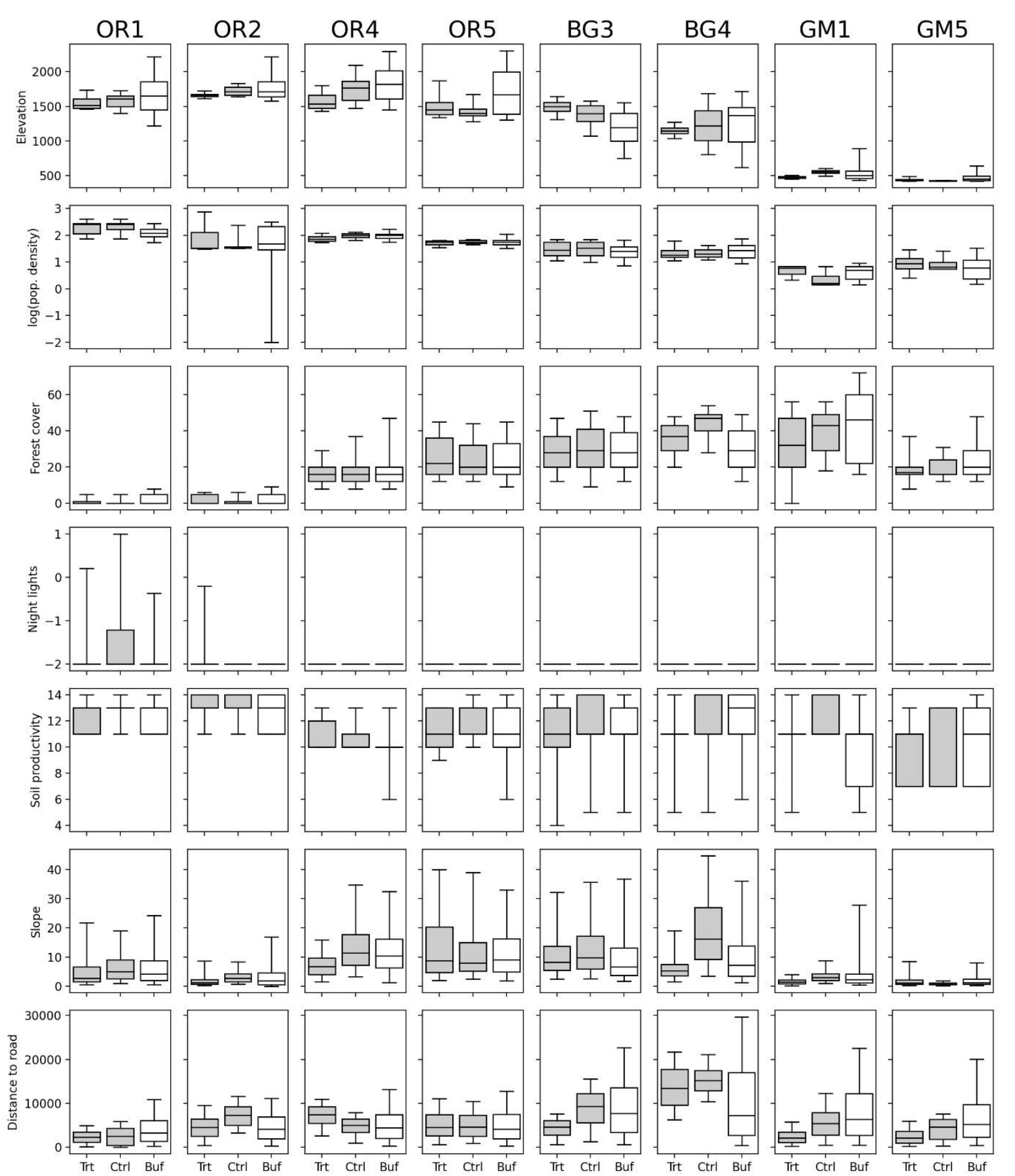

Fig. A4.2: Boxplots of the covariate distributions in each Treatment site, selected Control site, and 30km buffer from which the Control site was selected. The whiskers represent $5 \%$ and $95 \%$ percentiles of the data. Outliers are not shown. Note that the first stage only used four of these covariates (elevation, population, density, forest cover, and night lights) and the second stage used five (population density, forest cover, soil productivity, slope, and distance to road). 


\section{A4.2. Point Sampling and Reweighting}

\section{A4.2.1. Sample Size}

The spatial correlation of the sampled points generally increased with larger sample sizes (Table A4.1). We chose to progress with sampling 75 points from each site; beyond this level, statistically significant spatial autocorrelation is observed. We believe this achieves an appropriate balance between statistical power and spatial independence.

Table A4.1: P-values from Moran's I tests of spatial correlation in the residuals of logistic regressions with dependent variables $\mathrm{Y}_{1}$ (smallholder expansion) and $\mathrm{Y}_{2}$ (smallholder abandonment) for different sample sizes. Shaded cells indicate instances in which the spatial correlation is significant at the 5\% level.

\begin{tabular}{|c|c|c|c|c|c|c|c|c|}
\hline \multirow[b]{2}{*}{ Site } & \multicolumn{2}{|c|}{$\mathrm{N}=20$} & \multicolumn{2}{|c|}{$\mathrm{N}=50$} & \multicolumn{2}{|c|}{$\mathrm{N}=75$} & \multicolumn{2}{|c|}{$\mathrm{N}=100$} \\
\hline & $\mathrm{Y} 1$ & Y2 & $\mathrm{Y} 1$ & Y2 & Y1 & Y2 & Y1 & $\mathrm{Y} 2$ \\
\hline BG3 & 0.38 & 0.50 & 0.41 & 0.51 & 0.29 & 0.39 & 0.16 & 0.24 \\
\hline $\mathrm{BG} 4 \dagger$ & 0.11 & - & 0.10 & - & $0.10^{*}$ & - & $0.10^{*}$ & - \\
\hline GM1 † & 0.30 & - & 0.41 & - & 0.36 & - & 0.28 & - \\
\hline GM $5 \dagger$ & 0.12 & - & 0.13 & - & 0.21 & - & 0.21 & - \\
\hline OR1 & 0.36 & 0.43 & 0.37 & 0.29 & 0.34 & 0.15 & 0.23 & $0.08 *$ \\
\hline OR2 & 0.52 & 0.41 & 0.28 & 0.48 & 0.16 & 0.47 & $0.03 *$ & 0.42 \\
\hline OR4 & 0.54 & 0.44 & 0.32 & 0.50 & 0.13 & 0.50 & $0.06^{*}$ & 0.47 \\
\hline OR5 & 0.51 & 0.44 & 0.36 & 0.46 & $0.06^{*}$ & 0.46 & $0.01 *$ & 0.42 \\
\hline
\end{tabular}

$\dagger$ We did not assess this site's Y2 outcome because it initially contained less than $10 \%$ smallholder agriculture.

\section{A4.2.2 Covariate Balance}

In most cases, entropy balancing successfully removed all bias in the weighted Control data (Fig. A4.3). For covariates containing high levels of bias between the Treatment and unbalanced Control site (e.g., BG4), the entropy balancing successfully reduced bias to within acceptable levels (Austin, 2009). The rebalanced data for GM5 did contain some residual bias, however the rebalancing provided a substantial improvement and the levels of residual bias are not drastically high for any covariate.

We note that the original presentation of the entropy balancing algorithm was designed to yield a weighted set of Control observations with zero bias (Hainmueller, 2012). Specifically, the optimization formulation specifies balance in first (and potentially higher order) moments as constraints. However, our data unfortunately contained limited overlap in some covariates (Fig. A4.2), meaning that the algorithm did not always converge with the original balance constraint specification. We therefore modified the source code for the ebal $\mathrm{R}$ package to exit the algorithm's iteration when instabilities were detected. With this modification, we were able to calibrate a set of weights for each site and outcome that substantially reduced the bias across all covariates (Fig. A4.3). However, for some sites (e.g., GM5 for $\mathrm{Y}_{1}$ ), these weights were highly skewed, i.e., most points received almost no weight with several points receiving large weights (Fig. A4.4). We note this issue but for the purposes of this article do not delve more deeply into modifying or developing methods for entropy balancing. Some recent research is beginning to generalize entropy balancing to achieve approximate balance (rather than exact) (Xu and Yang, 2021), but the $\mathrm{R}$ implementations are still in development. 


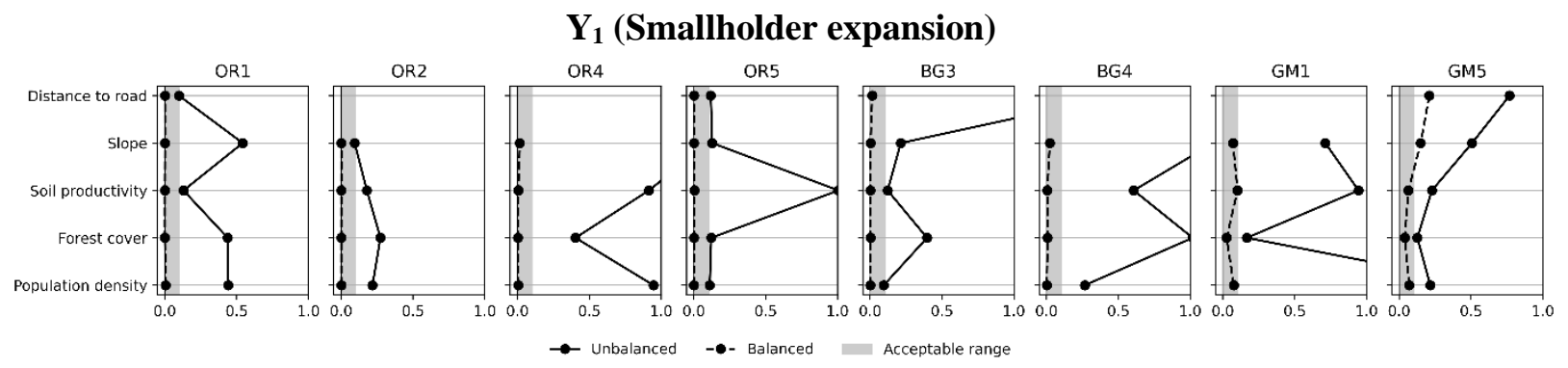

$\mathbf{Y}_{2}$ (Smallholder abandonment)
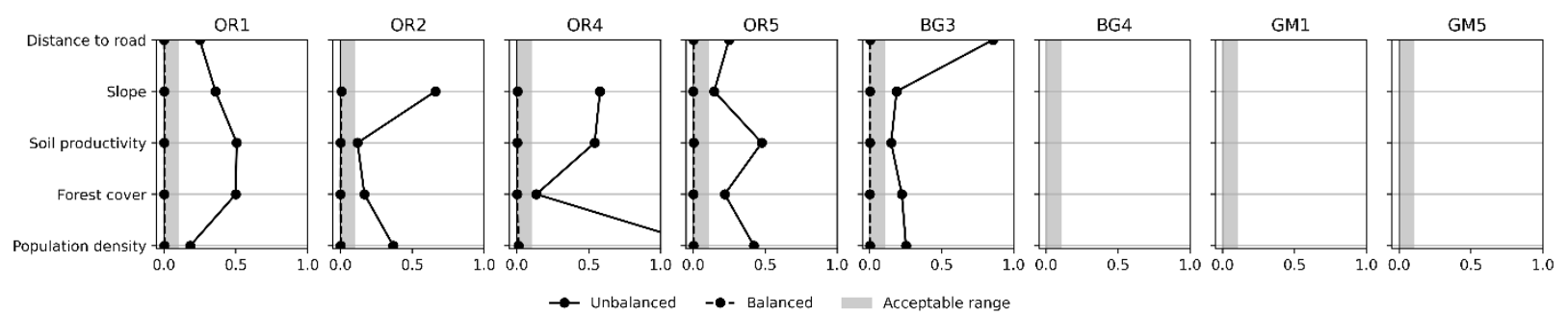

Fig. A4.3: Covariate bias for each covariate used in the second-stage rebalancing. The horizontal axes plot the absolute standardized mean difference (AMSD; Equation 1 in the main manuscript). BG4, GM1, and GM5 were excluded from the smallholder abandonment analysis $\left(\mathrm{Y}_{2}\right)$. The distance to road covariate was excluded in four sites (BG4, GM1, OR2, and OR4) due to limited overlap in these data between the Treatment and Control sites (Fig. A4.2).
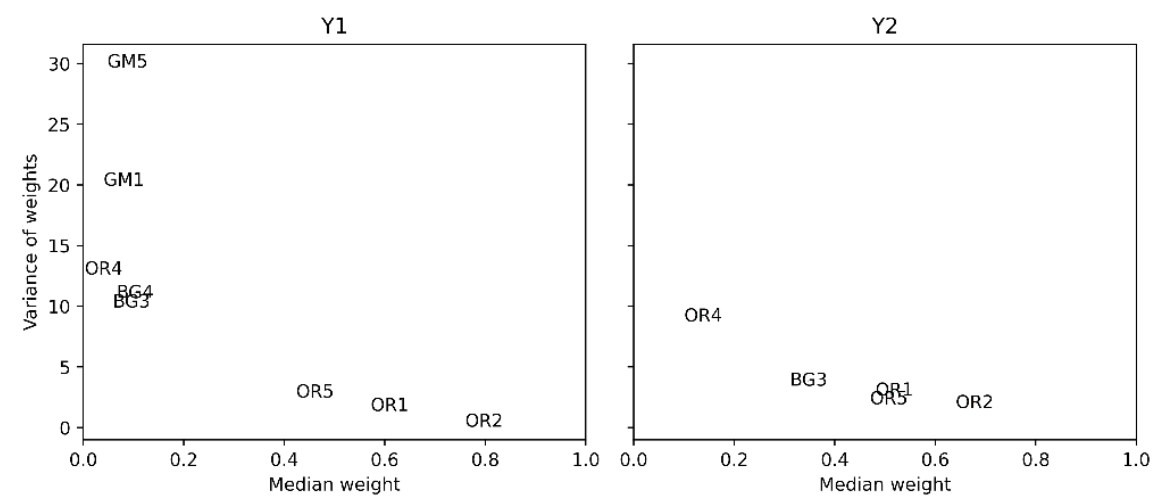

Fig. A4.4: Median and variance of resulting sample weights. 


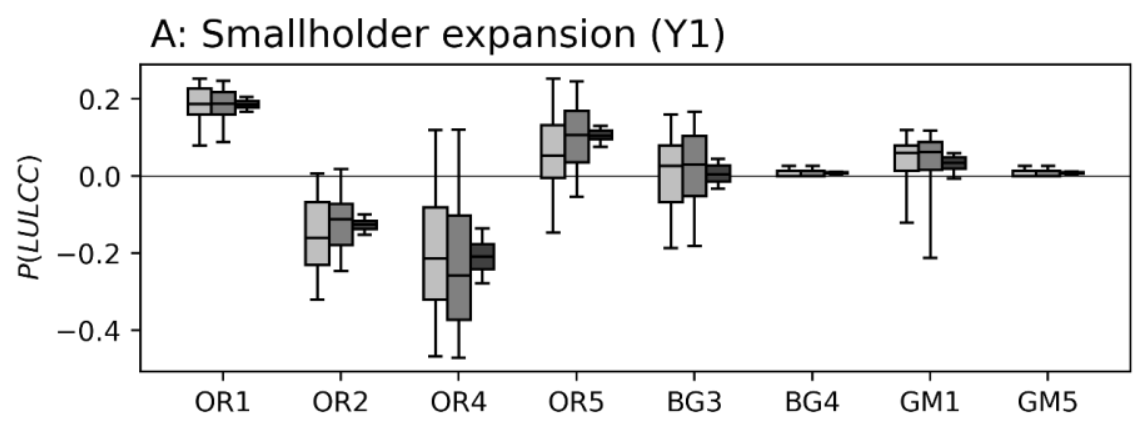

B: Smallholder abandonment (Y2)

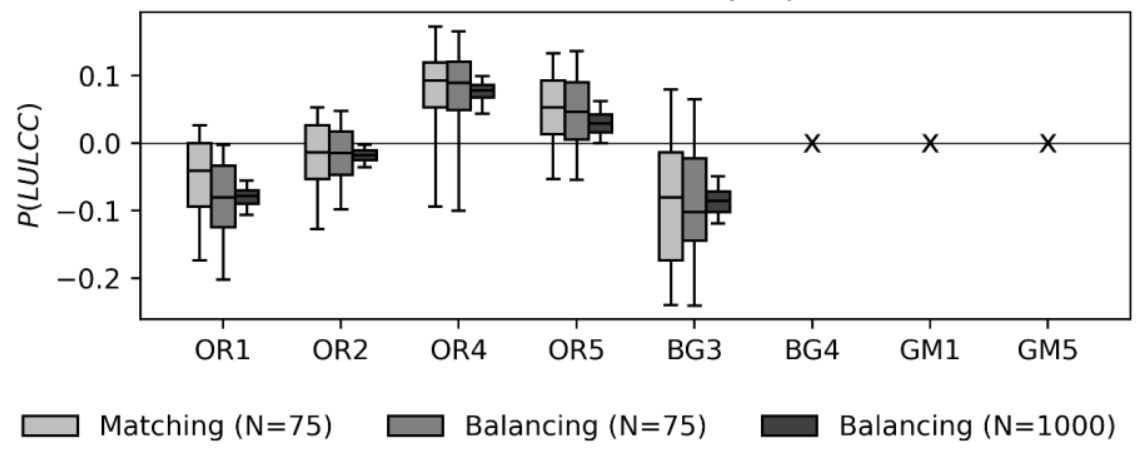

Fig. A4.5: Indirect LULCC estimates under different second-stage approaches. Matching $(N=75)$ used genetic matching with 75 points sampled from each Treatment and Control Site. Balancing $(N=75)$ used entropy balancing with 75 points and is the approach presented in the main manuscript. Balancing $(N=1000)$ used entropy balancing with 1000 points, which violate assumptions of spatial independence and consequently lead to lower variability in the estimated outcome.

\section{References}

Austin, P. C. 2009. "Balance Diagnostics for Comparing the Distribution of Baseline Covariates between Treatment Groups in Propensity-score Matched Samples.” Statistics in Medicine. https://onlinelibrary.wiley.com/doi/abs/10.1002/sim.3697.

Hainmueller, J. 2012. "Entropy Balancing for Causal Effects: A Multivariate Reweighting Method to Produce Balanced Samples in Observational Studies." Political Analysis: An Annual Publication of the Methodology Section of the American Political Science Association 20 (1): 25-46.

Xu, Y., and E. Yang. 2021. "Hierarchically Regularized Entropy Balancing.” Available at SSRN. https://doi.org/10.2139/ssrn.3807620. 